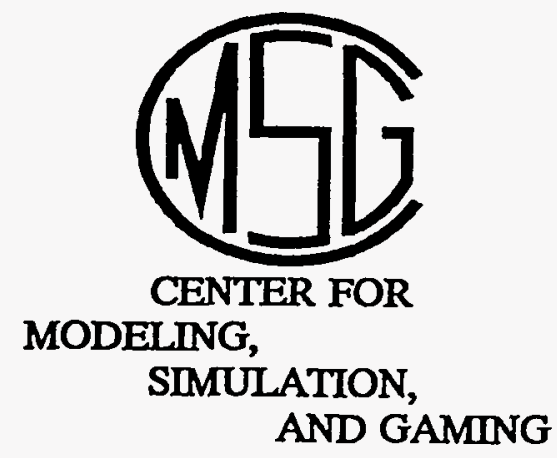

\section{AN INDEPENDENT VERIFICATION AND VALIDATION OF THE FUTURE THEATER LEVEL MODEL CONCEPTUAL MODEL}

D. S. Hartley III

Kara L Kruse

A John Martellaro

Stephen L Packard

Benjamin Thomas, Jr.

Victoria K. Turley

AUGUST 1994

MANAGED BY

MARTIN MARIETTA ENERGY SYSTEMS, INC.

FOR THE UNITED STATES

DISTRIBUTION OF THIS DOCUMENT IS UNLIMITED

DEPARTMENT OF ENERGY 


\section{DISCLAIMER}

This report was prepared as an account of work sponsored by an agency of the United States Government. Neither the United States Government nor any agency thereof, nor any of their employees, makes any warranty, express or implied, or assumes any legal liability or responsibility for the accuracy, completeness, or usefulness of any information, apparatus, product, or process disclosed, or represents that its use would not infringe privately owned rights. Reference herein to any specific commercial product, process, or service by trade name, trademark, manufacturer, or otherwise, does not necessarily constitute or imply its endorsement, recommendation, or favoring by the United States Government or any agency thereof. The views and opinions of authors expressed herein do not necessarily state or reflect those of the United States Government or any agency thereof.

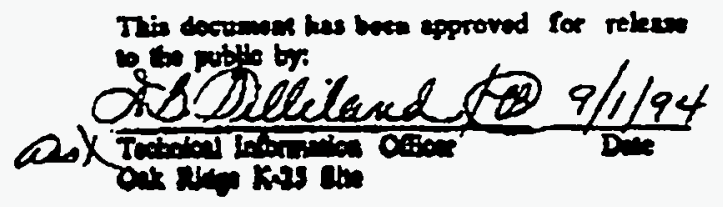




\section{DISCLAIMER}

Portions of this document may be illegible in electronic image products. Images are produced from the best available original document. 


\title{
AN INDEPENDENT VERIFICATION AND VALIDATION OF THE FUTURE THEATER LEVEL MODEL CONCEPTUAL MODEL
}

\author{
D. S. Hartley III \\ Kara L. Kruse \\ A. John Martellaro \\ Stephen L. Packard \\ Benjamin Thomas, Jr. \\ Victoria K. Turley
}

August 1994

Prepared for

The Joint Staff/J-8

The Pentagon, Room 1D940

Washington, DC 20318-8000

under DOE Project Number 2127-G104-A1

Prepared by

Data Systems Research and Development Program

Technical Operations

Oak Ridge K-25 Site

Oak Ridge, Tennessee 37831-7618

Managed by

MARTIN MARIETTA ENERGY SYSTEMS, INC.

for the

U.S. DEPARTMENT OF ENERGY under contract DE-AC05-84OR21400 


\section{EXECUTIVE SUMMARY}

Martin Marietta Energy Systems, Inc. is the Management and Operating Contractor for the Department of Energy's Oak Ridge National Laboratory and other Oak Ridge Federal Facilities. The Data Systems Research and Development (DSRD) Program is the unit of Energy Systems with principal responsibility for data systems work performed for other federal agencies, such as the Department of Defense. DSRD has considerable expertise in combat modeling, simulation and gaming and in performing independent verification and validation of combat models. Because of our expertise and our independence with regard to the Future Theater Level Model (FTLM), The Joint Staff/J-8 asked and received from the Department of Energy our aid in performing an independent verification and validation study of the FTLM.

We subjected the conceptual design of the FTLM to those tests that we thought appropriate to its design stage, to its purpose as an analytical combat model, and to its capabilities as specified in the Mission Needs Statement. The conceptual design passed those tests. We recommend that its development be continued.

Because this recommendation is positive, we recommend increased attention in the areas of design of model input and output support and decision logic creation. We also recommend the institution of informal configuration management control. These steps are appropriate as the model moves to a more complex and costly stage of development. We further recommend continuation of the planned integration of independent verification and validation into the FTLM design and construction process.

Dean S. Hartley III Principal Investigator FTLM IV\&V Team 


\section{CONTENTS}

LIST OF FIGURES $\ldots \ldots \ldots \ldots \ldots \ldots \ldots \ldots \ldots \ldots \ldots \ldots \ldots \ldots \ldots \ldots \ldots \ldots \ldots \ldots \ldots \ldots$

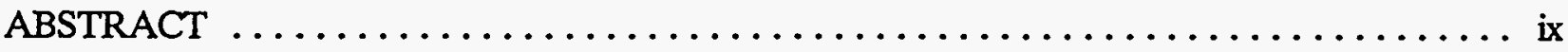

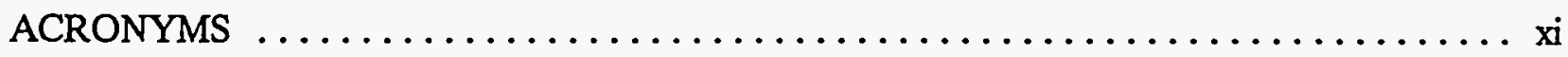

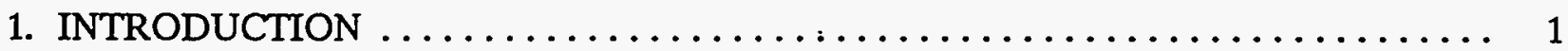

1.1 BRIEF PROBLEM STATEMENT $\ldots \ldots \ldots \ldots \ldots \ldots \ldots \ldots \ldots \ldots \ldots \ldots \ldots \ldots \ldots \ldots, 1$

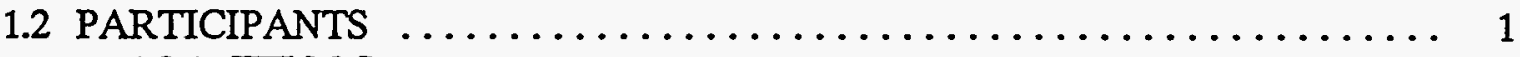

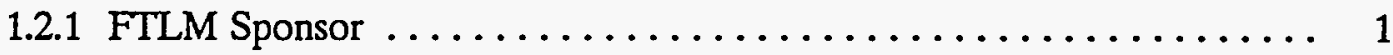

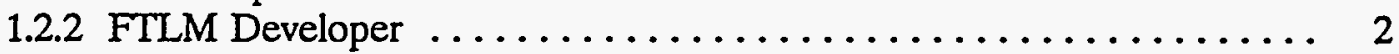

1.2.3 Performing Organization $\ldots \ldots \ldots \ldots \ldots \ldots \ldots \ldots \ldots \ldots, 2$

1.3 PURPOSE OF THIS DOCUMENT $\ldots \ldots \ldots \ldots \ldots \ldots \ldots \ldots \ldots \ldots, 2$

1.4 SCOPE OF THE DOCUMENT $\ldots \ldots \ldots \ldots \ldots \ldots \ldots \ldots \ldots \ldots \ldots, 2$

1.5 DOCUMENT ORGANIZATION $\ldots \ldots \ldots \ldots \ldots \ldots \ldots \ldots \ldots \ldots \ldots, 2$

2. DEFINITIONS AND STANDARDS $\ldots \ldots \ldots \ldots \ldots \ldots \ldots \ldots \ldots \ldots \ldots \ldots \ldots, 3$

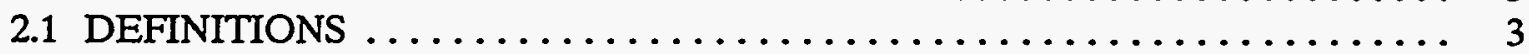

2.2 VERIFICATION STANDARDS - THE MISSION NEEDS STATEMENT $\ldots .3$

2.2.1 Modeling Deficiencies (Restated as FTLM Required Features) ...... 4

2.2.2 Current Modeling Capabilities (To Be Retained) ............ 4

2.2.3 Constraints on the FTLM $\ldots \ldots \ldots \ldots \ldots \ldots \ldots \ldots \ldots, 4$

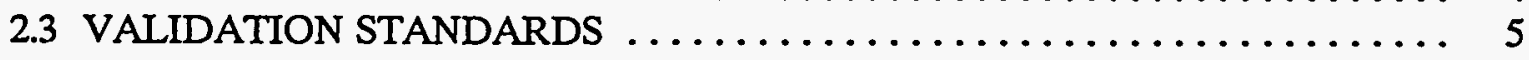

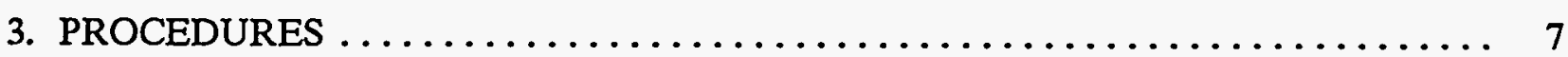

3.1 GATHER A GROUP WITH MANY TALENTS $\ldots \ldots \ldots \ldots \ldots \ldots \ldots \ldots, 8$

3.2 STUDY THE FTLM DOCUMENTATION $\ldots \ldots \ldots \ldots \ldots \ldots \ldots \ldots, 8$

3.3 COLLATE AND CIRCULATE THE FIRST IMPRESSIONS $\ldots \ldots \ldots \ldots \ldots, 9$

3.4 GENERATE PROACTIVE OPINIONS $\ldots \ldots \ldots \ldots \ldots \ldots \ldots \ldots \ldots, 9$

3.5 OBTAIN FEEDBACK $\ldots \ldots \ldots \ldots \ldots \ldots \ldots \ldots \ldots \ldots \ldots \ldots, 9$

3.6 CREATE A DRAFT REPORT $\ldots \ldots \ldots \ldots \ldots \ldots \ldots \ldots \ldots \ldots \ldots \ldots \ldots, 9$

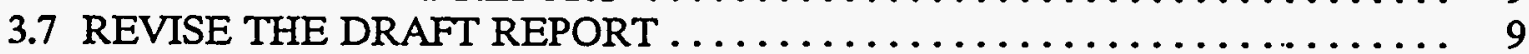

3.8 DELIVER THE DRAFT REPORT $\ldots \ldots \ldots \ldots \ldots \ldots \ldots \ldots \ldots \ldots, 9$

3.9 CREATE THE FINAL REPORT $\ldots \ldots \ldots \ldots \ldots \ldots \ldots \ldots \ldots \ldots \ldots \ldots \ldots \ldots$

3.10 DELIVER THE FINAL REPORT $\ldots \ldots \ldots \ldots \ldots \ldots \ldots \ldots \ldots \ldots \ldots, 10$

3.11 MONTHLY PROGRESS REPORTS $\ldots \ldots \ldots \ldots \ldots \ldots \ldots \ldots \ldots \ldots \ldots$

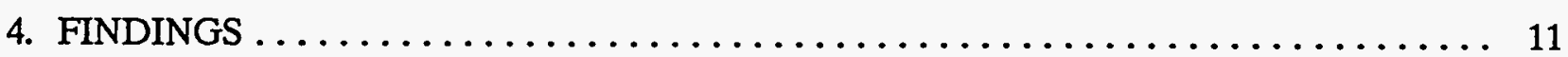

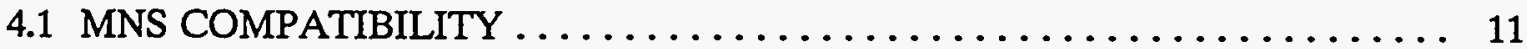

4.2 CRITICAL FLAWS $\ldots \ldots \ldots \ldots \ldots \ldots \ldots \ldots \ldots \ldots \ldots \ldots \ldots \ldots \ldots \ldots \ldots \ldots, 12$

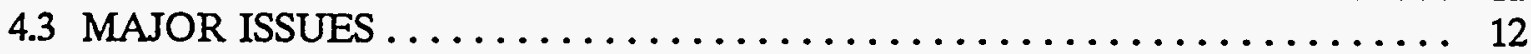




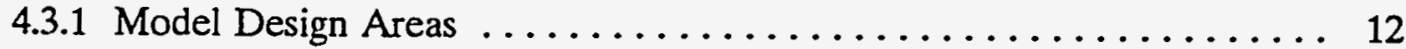

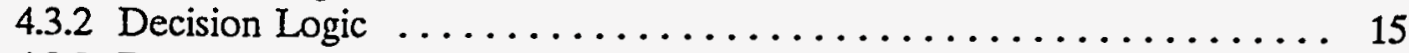

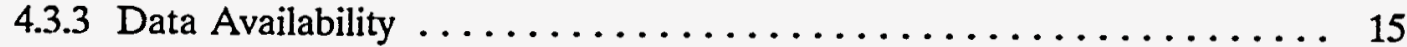

4.3 .4 Management ............................ 15

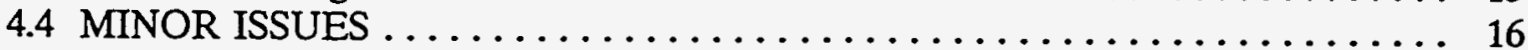

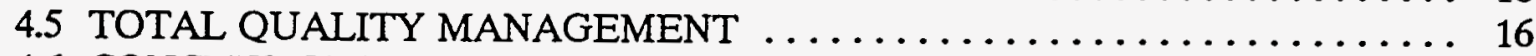

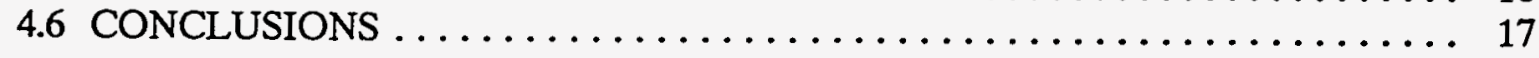

5. RECOMMENDATIONS $\ldots \ldots \ldots \ldots \ldots \ldots \ldots \ldots \ldots \ldots \ldots \ldots \ldots \ldots \ldots$

BIBLIOGRAPHY $\ldots \ldots \ldots \ldots \ldots \ldots \ldots \ldots \ldots \ldots \ldots \ldots \ldots \ldots \ldots \ldots \ldots \ldots$

APPENDIX: VERBATIM COMMENTS ..................... 25 


\section{LIST OF FIGURES}

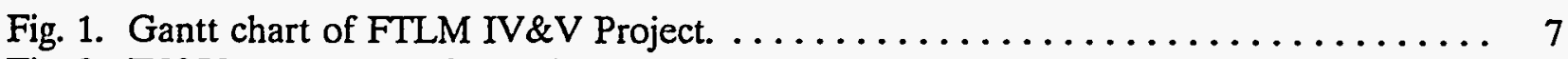

Fig. 2. IV\&V team areas of experience. $\ldots \ldots \ldots \ldots \ldots \ldots \ldots \ldots \ldots \ldots \ldots \ldots \ldots$

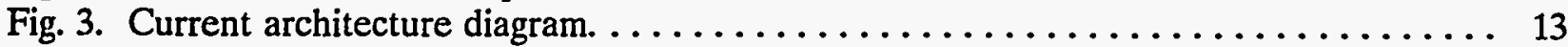

Fig. 4. New architecture diagram. ........................... 13 


\begin{abstract}
This report describes the methodology and results of independent verification and validation performed on a combat model in its design stage. The combat model is the Future Theater Level Model (FTLM), under development by The Joint Staff/J-8. J-8 has undertaken its development to provide an analysis tool that addresses the uncertainties of combat more directly than previous models and yields more rapid study results.

The methodology adopted for this verification and validation consisted of document analyses. Included were detailed examination of the FTLM design documents (at all stages of development), the FTLM Mission Needs Statement, and selected documentation for other theater level combat models. These documents were compared to assess the FTLM as to its design stage, its purpose as an analytical combat model, and its capabilities as specified in the Mission Needs Statement. The conceptual design passed those tests. The recommendations included specific modifications as well as a recommendation for continued development.

The methodology is significant because independent verification and validation have not been previously reported as being performed on a combat model in its design stage. The results are significant because The Joint Staff/J-8 will be using the recommendations from this study in determining whether to proceed with development of the model.
\end{abstract}




\section{ACRONYMS}

$\mathrm{C}^{3} \mathrm{I} \quad$ Command, Control, Communications, and Intelligence

CAS Combat Air Support

COA Course of Action

DBMS Database Management System

DSRD Data Systems Research and Development

EW Electronic Warfare

FEBA Forward Edge of the Battle Area

FLOT Forward Line of Troops

FTLM Future Theater Level Model

GUI Graphical User Interface

I/O Input/Output

IV\&V Independent Verification and Validation

$\mathrm{J}-8$ Force Structure, Resource and Assessment Directorate of The Joint Staff

MNS

MOE Mission Needs Statement

MRC Measure of Effectiveness

ORSBM Oak Ridge Spreadsheet Battle Model

$\mathrm{pK}$

TQM

V\&V

VIC

VV\&A

Probability of Kill

Total Quality Management

Verification and Validation

Vector-in-Commander

Verification, Validation and Accreditation 


\section{INTRODUCTION}

This report describes an assessment of a combat model. The reason for the assessment was to provide independent evidence for use in determining the future development course of the model.

\subsection{BRIEF PROBLEM STATEMENT}

The Joint Staff/J-8 has determined that a need exists for a new theater level model of combat to be used as an analysis tool. That model is currently called the Future Theater Level Model (FTLM). $\mathrm{J}-8$ is developing the model using standard Department of Defense techniques, under which various milestone criteria must be met before proceeding to the next development stage. As an aid to making these decisions, the procedures for this model require independent verification and validation of the model during its development.

\section{PARTICIPANTS}

The relevant groups involved in this project were the sponsor, the model developer, and the performing organization.

\subsubsection{FTLM Sponsor}

The sponsor of this project, and the sponsor of the FTLM development project, is the Force Structure, Resource and Assessment Directorate (J-8) of The Joint Staff. The FTLM project is located within the Analytical Tools Program, which is a program within J-8.

$\mathrm{J}-8$ has the mission and authority to:

- develop and improve analytical models, techniques and procedures used in studies and analysis; and

- develop analytical tools for use by the unified and specified commands.

The Mission Needs Statement (MNS) for the Analytical Tools Program within J-8 includes the following:

- apply operations research to conventional forces, large scale ground and air conflict, theater level, alternative force sizes, structures and mixes; and

- support the unified and specified commands capability assessment for joint, land, sea, and air combat. 


\subsection{FTLM Developer}

The sponsor, J-8, has obtained the services of the Operations Research Department of the Naval Postgraduate School for initial conceptual development of the FTLM. The Naval Postgraduate School has the intellectual resources of its staff and student body to draw from. The military, mathematical, and modeling experience that these resources represent was judged to be sufficient for the task.

\subsection{Performing Organization}

Martin Marietta Energy Systems, Inc. (Energy Systems) is the Management and Operating Contractor for the Department of Energy's Oak Ridge National Laboratory and other Oak Ridge Federal Facilities. The Data Systems Research and Development (DSRD) Program is the unit of Energy Systems with principal responsibility for data systems work performed for other federal agencies, such as the Department of Defense. DSRD has considerable expertise in combat modeling, simulation and gaming and in performing independent verification and validation of combat models. Because of our expertise and our independence with regard to the Future Theater Level Model (FTLM), The Joint Staff/J-8 asked and received from the Department of Energy the aid of DSRD in performing an independent verification and validation study of the FTLM.

\subsection{PURPOSE OF THIS DOCUMENT}

This document constitutes the principal deliverable that documents our findings on the status of the conceptual design of the FTLM. It contains our professional opinion on the verification and validation status of the FTLM.

\subsection{SCOPE OF THE DOCUMENT}

This document describes the general nature of the project and the standards used to measure the results. It describes the processes we used to test the FTLM against the standards and reports the results and our recommendations. It also includes the detailed comments that were forwarded to the sponsor and to the model designers.

\subsection{DOCUMENT ORGANIZATION}

This document is organized into six major sections. The first section (this one) is an introduction to the problem and the participants. The second section provides the definitions and standards used in the project. The third section describes the process of the project. The fourth section gives the overall results of the project. The fifth section contains our recommendations. The sixth section, an appendix, contains the detailed comments, questions, criticisms, and responses that were developed in the course of the investigation. A short bibliography of verification and validation literature is included in the end matter of this report. 


\section{DEFINITIONS AND STANDARDS}

To our knowledge, no previous combat model has undergone a formal independent verification and validation process while in the design stage. The general verification and validation (V\&V) literature is written with the assumption that either the computer model exists or, at least, a formal design exists. Neither is the case for the FTLM. We adapted existing procedures and definitions, based on our experience and the situation.

\subsection{DEFINITIONS}

Verification: the process of ensuring that a (computer) model reproduces the processes of the conceptual model correctly.

Validation: the process of ensuring that a model reproduces reality as appropriate to its intended use.

Independent Verification and Validation $(I V \& V)$ : a verification and validation project performed by a party other than the designer or the sponsor of a model.

IV\&V of a conceptual design: previously undefined. It is defined in the next two paragraphs.

According to the definition of verification, verification of a conceptual design has no content. However, for convenience in separating functions and by analogy, we will use this term to refer to correspondence of the conceptual design with the Mission Needs Statement. The operative question is, "does this design satisfy the Mission Needs Statement?"

Validation of a conceptual design has practical problems of its own. Where the design has been sufficiently refined to specify algorithms, we can determine whether the validity of the algorithm is known and question its applicability for the given situation. However, where the design is less specific, the question devolves to a determination of the likely success and completeness of an approach to a problem. Other issues that must be addressed are the overall completeness of the model and the appropriateness of levels of detail or resolution for the various parts of the model.

\subsection{VERIFICATION STANDARDS - THE MISSION NEEDS STATEMENT}

The MNS for the Stochastic Theater Combat Modeling project (which is the initiator of the FTLM) defines the scope and vision of the FTLM. The FTLM Mission Needs Statement is oriented on the missions and authority of the J-8 environment. It specifies the characteristics that the FTLM must have. It defines the attributes of the FTLM by listing deficiencies in available models that need addressing, stating current capabilities that should be included, enumerating constraints, and defining milestones. Thus the MNS provides the standards for verification. 


\section{Modeling Deficiencies (Restated as FTLM Required Features)}

The FTLM should

- take a short time to set up, run and analyze many and different friendly and enemy courses of action (COAs), operational concepts, threat employment scenarios, and force mixes;

- incorporate uncertainty in data, scenarios (multiple regional contingencies), processes, and represent and measure variability of theater outcomes;

- model joint and combined theater of operations with relatively smaller (compared to European scenarios of 70's and 80's) and highly mobile forces;

- incorporate operational command, control, communications and intelligence $\left(\mathrm{C}^{3} \mathrm{I}\right)$ explicitly, showing effects on outcomes; and

easily display and model maneuver-based warfare.

\subsection{Current Modeling Capabilities (To Be Retained)}

The FTLM should

- model air and ground combat in a joint theater, with naval impact on ground, littoral and air combat;

- model deployment and sustainment effects;

- model effects of chemical and nuclear weapons; and

- model effects of qualitative factors, such as leadership, training and morale.

\section{2 .3 Constraints on the FTLM}

The FTLM must

- have no extensive personnel requirements (J-8 personnel can set up, run and analyze the model);

- use J-8 standard hardware, software and operating system set, but also be portable to other hardware and operating systems;

- be written in Ada - unless waiver is asked for and given;

- have a complete mathematical description and tutorial for analysts describing how to convert the analyst's war to the model; and 
- incorporate independent verification and validation concurrent with design and test of the model.

\subsection{VALIDATION STANDARDS}

Validation standards are more fluid than are the verification standards. Essentially, the standards consist of the experience and knowledge of the personnel of the performing organization. This experience and knowledge is informed by the current state-of-the-art, as expressed in the code and algorithms of currently accepted combat models. However, none of these models have been truly validated, considerably reducing their value as standards. 


\section{PROCEDURES}

Because no procedures for doing IV\&V of a conceptual design existed, we adapted existing procedures, based on our experience and the situation. The methodology adopted for this verification and validation consisted of document analyses. Included were detailed examination of the FTLM design documents (at all stages of development), the FTLM Mission Needs Statement, and selected documentation for other theater level combat models. These documents were compared to assess the FTLM as to its design stage, its purpose as an analytical combat model, and its capabilities as specified in the Mission Needs Statement.

We created a ten step procedure for determining the contents of the FTLM design, evaluating the design, and reporting our findings. These steps are described below. As part of standard project procedure, we reported each month on progress and expenditures. The Gantt chart for these procedures is shown in Fig. 1.

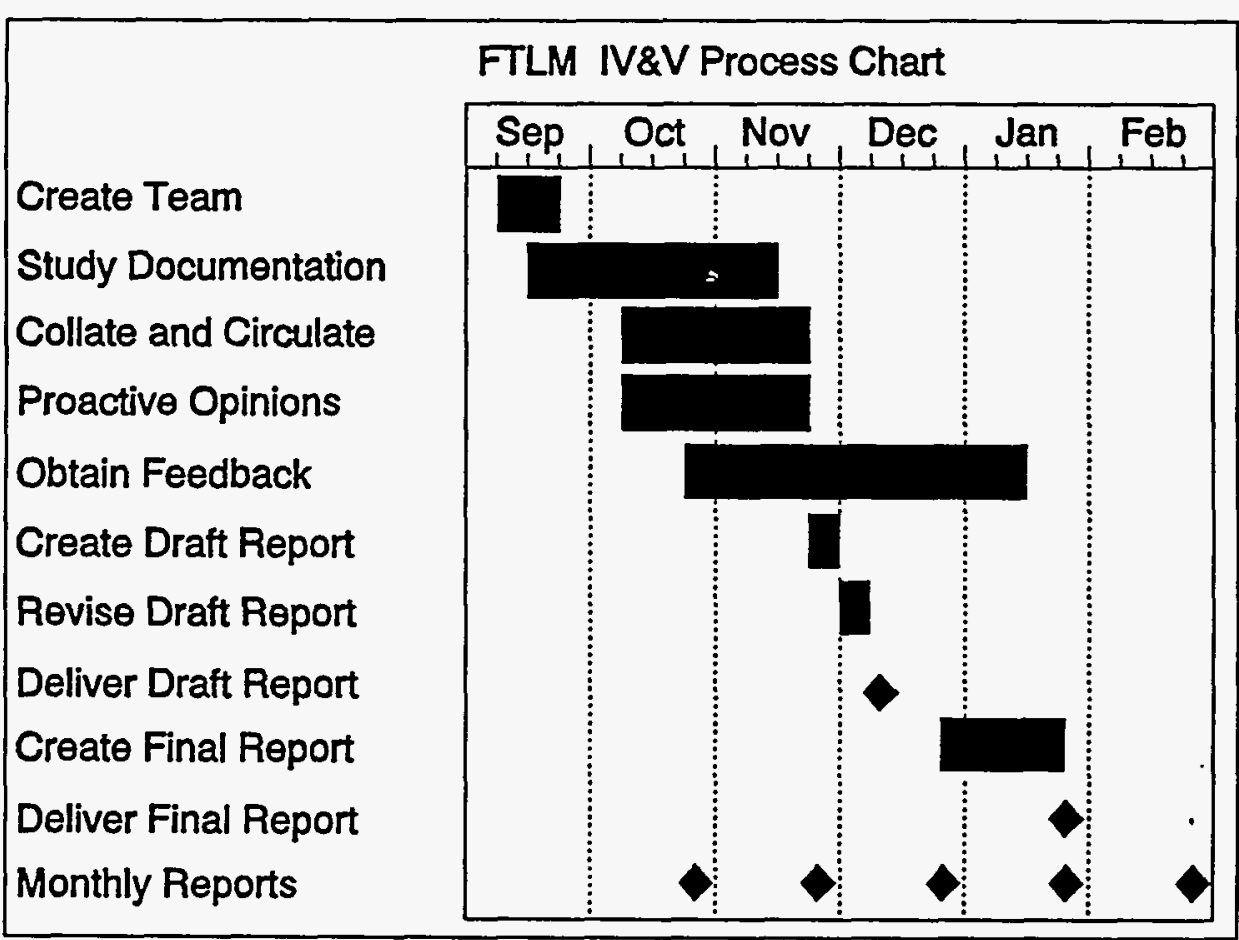

Fig. 1. Grantt chart of FTLM IV\&V Project. 


\subsection{GATHER A GROUP WITH MANY TALENTS}

The idea was to have as diverse a group as possible. The group size should be small enough to be workable, but large enough to ensure diversity of outlook and coverage of the technical disciplines. We ended up with six people. The skills cover the areas listed in Fig. 2.

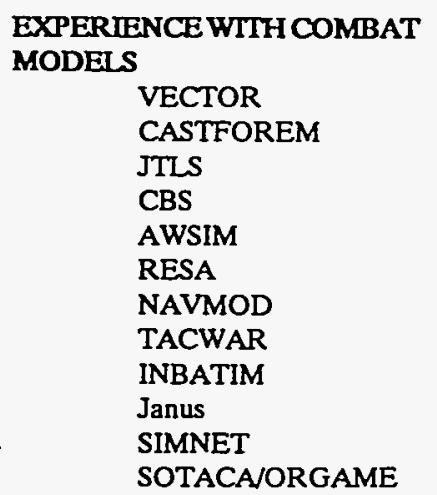

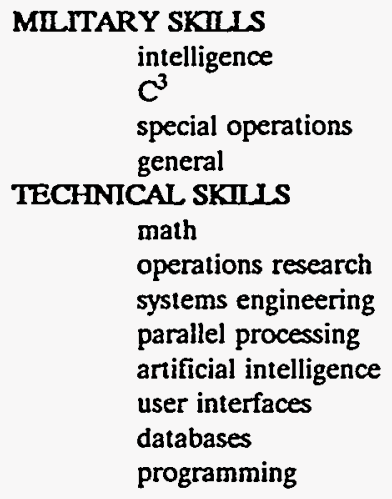

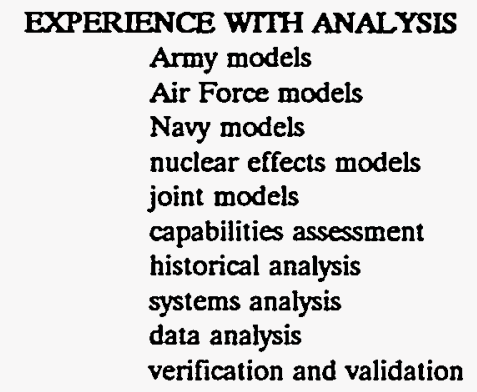

Fig. 2. IV\&V team areas of experience.

In some cases, the skills groups are more important than the particular skills within the group. For example, the primary reason for needing experience with combat models is the need for a generic understanding of the types of things combat models do and a knowledge of what algorithms are generally accepted by users for various parts of the models. Thus knowledge of the Army's CEM model would have been an acceptable substitute for knowledge of the VECTOR model. The military skills group is also important in the same fashion. Experience in this area is required to understand the subject being modeled.

In other cases, the particular skills within the groups are extremely important. Experience with analysis can be critical in determining relevance and significance of design issues to potential model uses. Some technical skills will fall into this category, depending on the particular model.

\subsection{STUDY THE FTLM DOCUMENTATION}

Each person individually read the central materials and produced comments based on his or her own conception of what would be useful to say. This maximized the number of approaches to the problem. Peripheral materials, such as documents for other models (TAC THUNDER, EAGLE, VIC, CASTFOREM, VECTOR, ORSBM, and ORGAME), and historical records of the FTLM project, were distributed so that each was read by at least two members. The project leader read everything. Each comment was tied to a model concept outline to permit brevity of comment.

A list of the documentation is included in the bibliography of this report. 


\subsection{COLLATE AND CIRCULATE THE FIRST IMPRESSIONS}

We collated and circulated the comments. This allowed each member to add to others' comments. As shown in Fig. 1, this step overlapped the second step. Once the first set of opinions had been entered, the value of independence of approach was confirmed and team members were free to modify their own approaches as desired. This overlap permitted us to build on each other's ideas rapidly and reduce redundancy to some extent.

\subsection{GENERATE PROACTIVE OPINIONS}

Members were asked to expand their view from reacting to the documentation to examining the broader picture of what should be in the concept and might be missing. This step also began the process of looking at the impact of the projected use of FTLM on its design requirements. This step proceeded concurrently with the collation and circulation step.

\subsection{OBTAIN FEEDBACK}

Periodically, the work in process was discussed with FTLM developers and J-8. This permitted some responses to questions asked by the team prior to writing the report. It also informed the sponsor of the status of the work. As shown in Fig. 1, this step started after the first part of the collation and circulation step and extended through a large part of the creation of the final report.

\subsection{CREATE A DRAFT REPORT}

The project leader created a unified view from the heretofore disjointed comments. This step began at the end of steps three (collation and circulation) and four (proactive opinions). Our organization of the comments (tying them to a model concept outline) and the fact that they were already in a word processing document made this a relatively short process.

\subsection{REVISE THE DRAFT REPORT}

The draft was circulated among the IV\&V team for comment and revised. This step was also short. The deadline for the finished draft report was defined by the need for J-8 to use it in the Milestone 1 review of FTLM.

\subsection{DELIVER THE DRAFT REPORT}

The final draft was submitted to J-8 on December 9, 1993, in time for its Milestone 1 review. 


\subsection{CREATE THE FINAL REPORT}

The Milestone 1 Review took place in late December 1993. Using feedback from the Milestone 1 Review, we have revised the Draft Report, creating this report, the Final Report. This process was to be longer than that required by the step to create the Draft Report, as shown in Fig. 1, because it included format editing, formal documentation reviews, and clearance and release procedures.

Because we had not exhausted the funding, J-8 asked us to delay delivery of the final report until the end of Fiscal Year 1993. The reason was to permit any significant changes to be reported. No major modifications have been required, although some stylistic changes have been made to the document.

\subsection{DELIVER THE FINAL REPORT}

The final report is being submitted and distributed during August 1994.

\subsection{MONTHLY PROGRESS REPORTS}

Each month we reported on the activities of the month, the planned activities for the next month, and the expenditures and funds remaining. These reports supplemented the informal discussions and feedback secessions. 


\section{FINDINGS}

We put the results of the independent verification and validation study of the FTLM Conceptual Model into four categories: MNS compatibility, critical flaws, major issues, and minor issues. The MNS compatibility issues are verification issues and the rest are validation issues. A model with a critical flaw is worthless or has serious restrictions on its domain of value. When applied to a model in development, this category means that immediate corrective action is required. Major issues are issues that degrade the value of a model. The implication here is that increased attention and resources will be required in the next stages of model development to prevent such degradation. Minor issues are defined as areas in which relatively minor efforts are required to correct problems. Failure to correct a minor problem might still have serious effects on the model's value. The implication for the FTLM is that attention needs to be placed in an area to prevent the actual occurrence of a problem.

\subsection{MNS COMPATIBILITY}

There were no obvious problems with satisfying the demands of the MNS; however, not all MNS areas were explicitly addressed in the material we examined. Our verbatim comments are given in Section 6 of the Appendix. Technically, these comments represent negative verification results; however, these are not serious flaws, given the state of the design. The comments are summarized in this sub-section.

Three MNS requirements will be critical determinants of the ultimate usefulness of the FTLM. They must be addressed in the next development phase.

- One FTLM goal is to reduce the total study turn-around time. There should be metrics associated with this goal. Directly: How long does a study currently take? (A range of values is appropriate.) How long should an FTLM study take? Indirectly: How much data is required for a current study? How much will FTLM require? What is the planned FTLM run-time for one replication? How many replications will be required? How many different friendly and enemy courses of action will a typical scenario require? The use of a multiprocessing computer that can run many replications simultaneously may be part of the solution; however, attention to reducing the pre- and post-processing times is mandatory.

- A related goal is a requirement for a small support team to run FTLM. Metrics are needed for this goal, also.

- The hardware, software and operating system requirements are not completely clear. Do the requirements for "standard" equipment restrict the use of multiprocessor computers and enhancements to user interface equipment? Do the Ada requirements prevent the use of modern object-oriented programming, which appears to have a definite place in the development of this model? We recommend considering the $\mathrm{C}^{++}$language. 
There are several modeling questions that have been left open. These questions are less challenging technically than those addressed in the conceptual design phase; however, they need to be answered in the next development phase.

- How will naval impacts be implemented?

- How will variable introductions of forces and materiel and variations in sustainment be modeled?

- How will chemical and nuclear weapons be modeled?

- How will qualitative factors, such as leadership, training and morale be modeled?

The requirement for a complete mathematical description and tutorial has not yet been confronted, but is certainly an extremely important factor in making the final model usable.

The requirement for continued IV\&V concurrently with design and test will be very important in producing a practical model.

\subsection{CRITICAL FLAWS}

We found no critical flaws in the design of the FTLM.

\subsection{MAJOR ISSUES}

The major issues can be grouped into four categories, Model Design Areas, Decision Logic, Data Availability, and Management. Our verbatim comments on major issues are found in Section 7 of the Appendix. The comments are summarized here.

\subsubsection{Model Design Areas}

Four major design areas have not been formally addressed in the FTLM design process. We can illustrate the problem by examining the current structural diagram in Fig. 3 and comparing it to a revised structural diagram, shown in Fig. 4.

As shown in Fig. 3, the FTLM design documents identify the areas of Analytic Structure and Environment as areas with comparable importance to those of Maneuver, Attrition, $\mathrm{C}^{3} \mathrm{I}$, and Logistics; however, two other equally important areas have been left out: Input Tools and Data Storage. In Fig. 4, the four operational areas have been grouped together and the four areas concerned with input and output (I/O) have been grouped together. The Analytic Structure area has been renamed Analytic Tools and refers to the tools used for analyzing the model output. The Data Storage area label indicates that a database management system (DBMS) will be needed for data storage. 
The input and output areas have been addressed, but only informally; i.e., some thought has been given to these areas and concepts have been put forward and tested. However, the level of attention has been relatively low and must be raised significantly.

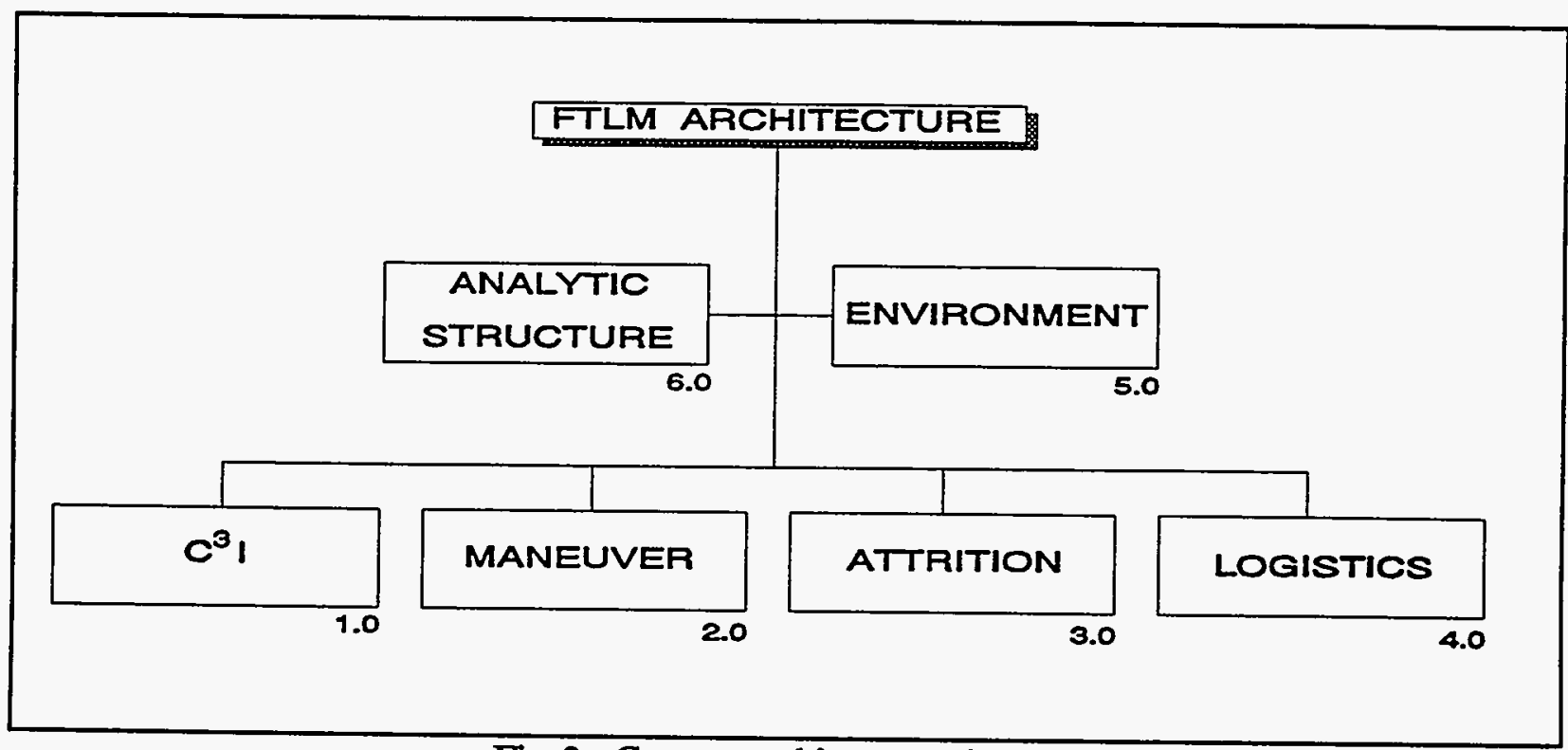

Fig. 3. Current architecture diagram.

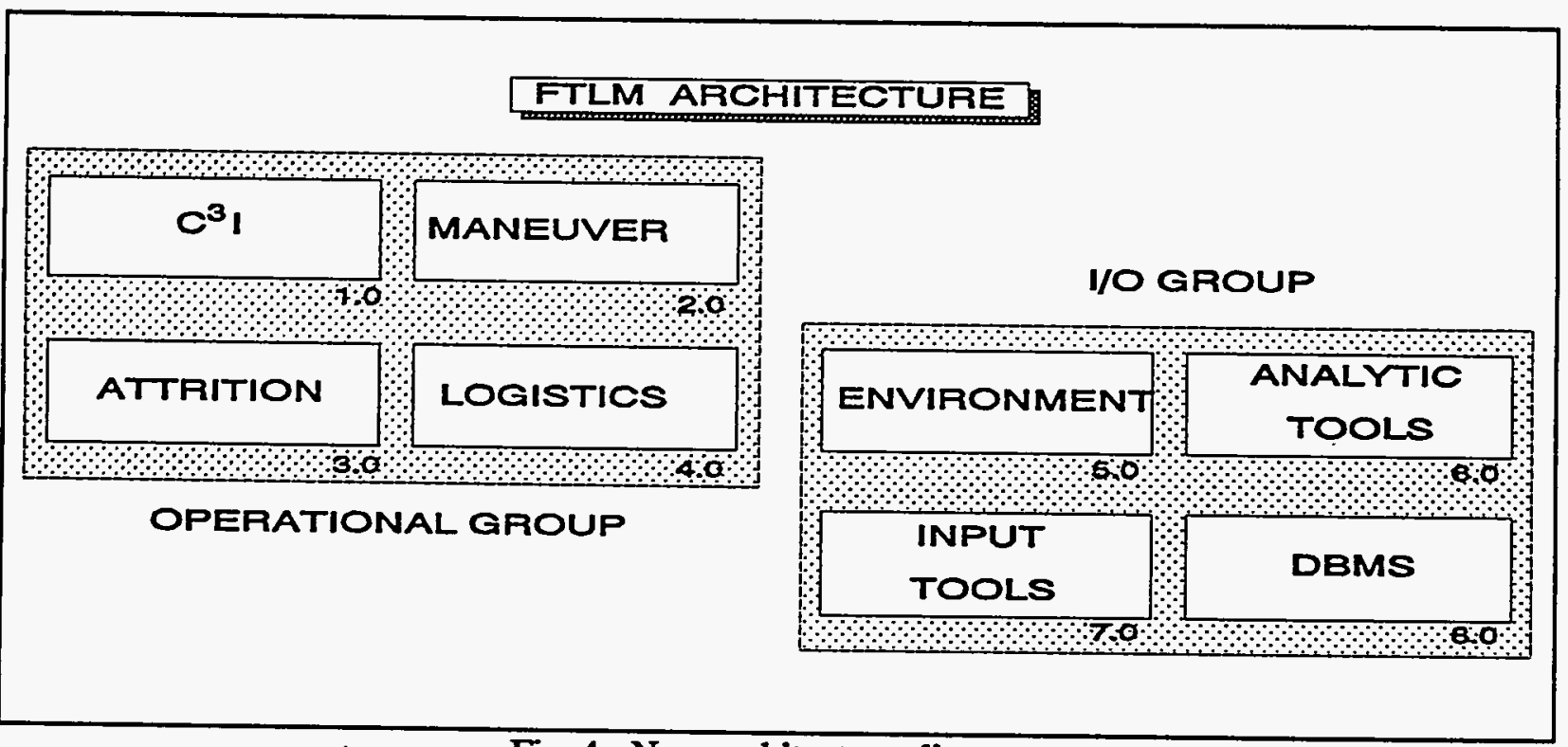

Fig. 4. New architecture diagram. 


\subsubsection{Input tools}

One of the major things to be learned from experiences with other models is the need for designing a good user interface at the beginning of model development. This greatly reduces the total system cost, decreases the number of people needed to run the model, increases the flexibility of the model, vastly decreases the turn around time for a study, permits more and better post-run analyses, and ensures better quality by reducing errors in the study.

The design for the FTLM user interface and tool set needs to consider the types and volume of data, the methodology used to store the data, the hardware and software constraints, and, most importantly, what the FTLM users will need to do. Current technology indicates the solution will include an object-oriented graphical user interface (GUI), tied to a flexible DBMS, with access to graphical and analytical tools. The users will be creating, modifying and validating the FTLM input which will include geographically referenced data and multiply connected data. One tool might deal with constructing and validating the networks; another might aid in selecting and tailoring units from databases and placing them geographically and temporally; and a third might check for consistencies of various sorts.

Another important tool that will be needed is a cataloger of input datasets. FTLM may require a larger set of scenario variants than required by previous analytic models. This cataloger would aid in the creation of each variation (probably as a shell for more detailed tools), ask for verbal descriptions (added to the base case description), and create names for each variant. Naturally, it would be tied to the analysis tools.

\subsubsection{Data}

The design team needs to begin formulating the FTLM data management plan. The FTLM will need storage for raw data to be used in creating input datasets, storage for the input datasets themselves, and storage for output datasets. Considerations of importance are automatic data validation support, support for update through graphical objects (for instance, changing a unit's geographical position in the database by moving its icon on a map), ability to interface with the input and output functions of a model, and standard DBMS attributes and functions. Object Orientation may be a major plus for the DBMS.

\subsubsection{Analytic tools}

As with the input interface, the output analysis needs to be planned now. The measures of effectiveness (MOEs) that are needed to interpret results need to be defined and factored into the design of the FTLM. For example, if territorial ownership over time is such an MOE, the correct data must be output from the FTLM to support the MOE. Ownership can be calculated using the concept of neighbors from cellular automata, that is, node (and link) ownership depends on proximity to and/or time since last occupancy by a combatant. Should this be calculated after the model run from a history of the nodes or should it be calculated within the model? The answer partly depends on whether node ownership information would be useful within the model, e.g., in making certain decisions. In addition to specific purposes, the FTLM output should be designed with interoperability with a statistical software package, such as SAS. 


\subsubsection{The environment}

This model design area has been only loosely defined to include political and physical constraints, such as excluded territory, airlift capacity and weather. Its definition needs to be clarified and integrated with the other areas. There are probably database design implications and modeling implications that need attention.

\subsubsection{Decision Logic}

A major issue concerns the production of decision logic. This will be an extremely significant part of the working of the entire model. Great care needs to be exercised.

There is not enough discussion about the rule sets, how they are specified, implemented, tested and validated, created, modified, and maintained. A tool for decision logic may be needed to ensure that each hook is correctly matched when a rule is changed and that no extraneous code is changed.

\subsubsection{Data Availability}

This is a major issue and concerns the effects of data availability on proper design. A design that does not take data availability into account may cause serious operational problems in using the model. Missing data within a category can be produced by interpolation, e.g., a data value for a particular weapon type can be derived from the weapon's similarities to other weapons. However, a missing class of data produces a conflict in combat model design. Should the model be designed to use the data that exist, despite flaws, or should the model require that proper data be created?

The volume of the data required for a theater level model necessitates the decision that only small changes can be made to the existing store of data types. Only the most important modeling problems have the stature to justify insistence on new data definitions. All other data requirements must be satisfied by existing data. Thus, most modeling questions must be driven by the need to use existing data.

The standard must be that data inputs must derive from known sources. Exceptions can be granted; but, they must be justified. The justification should be the importance of the unique data and the total burden (over all such decisions) should be extremely small.

A task needs to be started to identify available and required data types. Sources for non-US, nonNATO, and non-WARSAW PACT data need to be identified. Both current and "obsolete" weapons data will be needed.

\subsubsection{Management}

Two issues are included in management. These issues are not as urgent as the others; however, they do need to be addressed in time. One covers documentation planning. The other covers planning and control of the model construction process itself. 


\subsubsection{Documentation}

The MNS identifies a need for documentation of mathematical algorithms. The thrust appears to be toward ensuring that the analyst understands how to convert his real-world problem into a proper FTLM problem. This is the correct emphasis; however, it needs to be extended beyond mathematical algorithms to include guides for other areas, such as creating networks that model desired features and creating good decision rules. It also needs to include lessons on how to interpret FTLM results.

\subsubsection{Control of model development}

FTLM will ultimately need a formal configuration management process. Our experience has been that the proper time for instituting this is when there is a completely coded, working model. The model is considered to be working in the sense that it runs, not that it produces the correct answers. Instituting configuration management prior to this stage delays progress and does not improve results. However, we strongly recommend implementing an informal configuration management process.

The informal configuration management consists of a set of lists of things to do. The issues described in this section and detailed in the Appendix provide a starting point. The concept is to support the proper allocation of development resources by the technical manager. This manager can use the list to maintain a balanced development process. Any developer with a software process maturity level of three or higher will realize this need and act accordingly.

\subsection{MINOR ISSUES}

Most of our questions have been discussed with either the sponsor or the FTLM Project Team. Those that we determined were based on our misunderstandings have been omitted. However, some misconceptions may remain. Some of our questions have been answered satisfactorily, but are retained to confirm those answers and to ensure complete communication among all parties. Some of the points we make are cautionary in nature, rather than responses to parts of the concept. We have attempted to organize these questions and comments to permit easy reference to the part of FTLM that is impacted; however, some areas necessarily interact, making perfect alignment impossible. Our verbatim comments are given in Sections 1-5 of the Appendix.

\subsection{TOTAL QUALITY MANAGEMENT}

Total Quality Management (TQM) is a far-reaching concept. In industrial production, one of its corollaries is that it is better to build quality into the product than to try to inspect it in. This same concept is applicable to the creation of a combat model. The standard verification and validation techniques are designed for inspecting quality into models. That is, one looks for flaws in a (completed) model and tries to patch it. In contrast, the design and construction process for the FTLM includes independent verification and validation throughout the entire process. This is an excellent example of TQM. Not only does it permit the early, and relatively inexpensive, option of stopping work that will not provide cost-effective benefits, but it also permits the modification of the product toward higher quality at the earliest opportunity. 
The FTLM Mission Needs Statement is another example of TQM. The availability of such a document before commencing work permits review of the justification for the project. Given approval of the Mission Needs Statement, this document is the basis for testing the model's conceptual design. This process may appear to be only common sense; however, there have been many large, expensive models that were produced without a formally reviewed Mission Needs Statement, or even a clear idea of what the model should do and why it should do it.

\subsection{CONCLUSIONS}

The initial goal of any V\&V project is to search for flaws. It is not surprising that a report on the findings of such a project is full of model problems. These findings are important and the design team of the FTLM needs to take note of them; however, it is important to have the proper perspective. In general, the problems that we have found are not errors; they define objectives for the next stage of the development process. We see the FTLM as having the promise to merit a next stage in its development. Its concept is a good concept, one that addresses real needs of military analysis. Further, the TQM philosophy being used in its design increases the prospects for success. 


\section{RECOMMENDATIONS}

Our basic recommendation is that development of the FTLM continue. This model, in concept and in initial execution, promises to deliver new and much needed capabilities to the analysis community.

Our second recommendation concerns the major issues. Each of the major issues involves the allocation of resources, both monetary and management attention. These issues are classified as major issues because of the leverage they have on the quality of the final result. Given the scarcity of resources, allocating more effort to these areas will extend the time to completion of the FTLM. However, this extension is justified because, without early and meaningful attention to these issues, the model will require post-completion modifications that will be time consuming, expensive and unsatisfactory.

Our third recommendation concerns the minor issues and the congruence of the FTLM design and the MNS. At this point in its development, the FTLM requires an informal configuration management process (as described in the major issues). Each of the minor issues and each missing element of the MNS becomes an element of a list. The technical manager uses the lists to decide on the sequence and resolution of each item. The discipline will pay off as the model moves into the coding phase. Not only will it facilitate transition to the more stringent configuration management required for coding the model, but it will also make the procurement and management of the coding significantly easier.

Our final recommendation is that the model undergo further IV\&V as it develops. 


\section{BIBLIOGRAPHY}

FILM DOCUMENTATION (Sorted by Date)

J-8, (1992), Stochastic Theater Combat Modeling MISSION NEEDS STATEMENT.

Gaver, D. P., P. A. Jacobs, B. Marsh-Jones, S. H. Parry, (Feb 1992), Theater-Level Combat Modeling (Progress Report).

Youngren, Mark, (4 Mar 1992), On the Valuation of Forces.

Gaver, D. P., (15 Mar 1992), Physical Theater.

Youngren, Mark, (10 Apr 1992), Planning Functions.

Youngren, Mark, (24 Apr 1992), FTLM Architecture Specification.

Youngren, Mark, (13 May 1992), Future Theater-Level Model.

Parry, Sam, (15 Jun 1992), STOCWAR-SOME DESIGN AND IMPLEMENTATION CONCEPTS.

J-8, (26 Jun 1992), Stochastic Theater-Level Modeling.

Parry, Sam, (27 Jun 1992), STOCHWARS - TOP LEVEL FUNCTIONS.

Youngren, Mark, (7 Jul 1992), Some Thoughts on the Detection Process.

Youngren, Mark, (13 Jul 1992), Output Measures.

Youngren, Mark, (13 Jul 1992), Some Thoughts on the Detection Process.

Youngren, Mark, (17 Jul 1992), Using FTLM.

Youngren, Mark, (27 Jul 1992), Physical Representation - Arc-Node Network.

Youngren, Mark, (27 Jul 1992), Internal Decisions.

J-8, (5-6 Nov 1992), Meeting Notes.

Parry, Sam, (21 Nov 1992), Future Theater Level Model Air Module Design.

Youngren, Mark, (21 Dec 1992), Ground Maneuver. 
Gaver, D. P. and P. A. Jacobs, (Dec 1992), Sensor Fusion Models I.

Gaver, D. P. and P. A. Jacobs, (Dec 1992), Models for Sensor Data Fusion II.

Gaver, D. P. and P. A. Jacobs, (Dec 1992), Sample Operational Scenarios for STOCHWARS Simulation.

J-8, (5-7 Jan 1993), Meeting Notes.

Youngren, Mark, (22 Jan 1993), Missions.

Naval Postgraduate School, (1 Feb 1993), Research Proposal.

Youngren, Mark, (3 Feb 1993), FTLM Variable List.

Youngren, Mark, (3 Feb 1993), Action Unit Perception.

J-8, (17 Feb 1993), Meeting Notes.

J-8, (19 Feb 1993), Meeting Notes.

Gaver, D. P., (1 Mar 1993), Inference on Transit Time.

Gaver, D. P. and P. A. Jacobs, (2 Mar 1993), Allocation of Sensor Efforts (revised).

Youngren, Mark, (4 Mar 1993), The Perception Model at the Node.

Youngren, Mark, (8 Mar 1993), Model Input/Output.

Parry, Sam, (8 Mar 1993), Air Network \& Recon/Early Warning - Mission M8.

Youngren, Mark, (10 Mar 1993), Comments on Air Model Notes by Sam Parry.

Youngren, Mark, (18 Jul 1993), Ground Maneuver.

Youngren, Mark, (19 Jul 1993), Future Theater-Level Model (FTLM) Summary of Concept Design: Part $I$.

Youngren, Mark, (Aug 1993), Future Theater-Level Model (FTLM) Summary of Model Concept.

Schmidt, Karl Morris, (Sep 1993), Design Methodology for FTLM, Thesis, Naval Postgraduate School, Monterey, CA.

Youngren, Mark, (5 Oct 1993), Some Ideas About the Logistics Model.

Youngren, Mark, (5 Oct 1993), Tasks for FTLM Rule Set Development. 
J-8, (28 Oct 1993), Future Theater Level Model (FTLM) Methodology Review.

\section{DOCUMENTATION FOR OTHER MODELS (Sorted by Date)}

Hartley, Dean S., III, ed. (1975), Vector-1 System for Simulation of Theater-Level Combat, National Military Command System Support Center, TM 109-75.

AFSAA, (1985), TAC THUNDER Analyst's Manual.

SYSCON Corporations, (1988), Analyst Guide (Joint Theater Level Simulation), D-J-00013-C.

Hoffman, Camillus W. D., (1988), CASTFOREM: Scenario Writer's Guide, TRADOC, TRAC-WSMR-TD-R-88.

Smith, O. L., (1989), ORGAME: A Fast Interactive Model for Contingency Analysis, Martin Marietta Energy Systems, Inc., ORNL/DSRD/TM-46.

Mackey, D. C., et al., (1990), CASTFOREM: Methodologies, TRAC-WSMR, TRAC-WSMR-TD-4-88.

US ARMY TRAC, Command and Control Concept Paper (EAGLE model documentation).

Hartley, Dean S., III, (1991), Users' Guide to the Oak Ridge Spreadsheet Battle Model, Martin Marietta Energy Systems, Inc., K/DSRD-413.

US ARMY TRAC, (1992) Vector-In-Commander (VIC) Version 5.0 Documentation, disk version.

\section{THEORETICAL VERIFICATION, VALIDATION \& ACCREDITATION (VV\&A) (SOIted by Date)}

Naylor, Thomas H. and J. M. Finger. "Verification of Computer Simulation Models." Management Science 14, 2 (Oct 1967): B92-B106.

McKenney, James L. "Critique of: 'Verification of Computer Simulation Models'." Management Science 14, 2 (Oct 1967): B102-B103.

Schrank, William E. and Charles C. Holt. "Critique of 'Verification of Computer Simulation Models'." Management Science 14, 2 (Oct 1967): B104-B106.

Kleijnen, Jack P. C. Statistical Techniques in Simulation Part I. New York: Marcel Dekker, Inc., 1974.

Kapper, Francis B. "Wargaming I: The Simulation of Crisis." Defense/81. Arlington, VA: American Forces Information Service, May 1981, 14-21. 
Hoeber, Francis P. Military Applications of Modeling: Selected Case Studies, s. New York: Gordon and Breach Science Publisher, 1981.

Law, Averill M. and W. David Kelton. Simulation Modeling and Analysis. New York: McGraw-Hill Book Company, 1982.

Balci, Osman. "Credibility Assessment of Simulation Results." Proceedings of the 1986 Winter Simulation Conference. Ed. J Wilson J Henriksen S Roberts. 1986, 38-44.

Schmidt, J. W. "Introduction to Systems Analysis, Modeling and Simulation." Proceedings of the 1986 Winter Simulation Conference. Ed. J Wilson J Henriksen S Roberts. 1986, 5-16.

Sargent, Robert G. "Overview of Verification and Validation of Simulation Models, An." Proceedings of the 1987 Winter Simulation Conference. Ed. A Thesen; H Grant; W D Kelton. Atlanta, GA:, 1987, 33-39.

Balci, Osman. "How to Assess the Acceptability and Credibility of Simulation Results." Proceedings of the 1989 Winter Simulation Conference. Ed. E MacNair, K Musselman, P Heidelberger. Washington, DC:, 1989, 62-71.

Williams, Marion L., and James Sikora (1991), "SIMVAL Minisymposium-A Report," Phalanx, Vol. 24, No. 2, June.

Davis, Paul K. 1992. Generalizing Concepts and Methods of Verification, Validation, and Accreditation (VV\&A) for Military Simulations. RAND, R-4249-ACQ.

\section{PRACTICE OF VV\&A (Sorted by Date)}

Hartley, Dean S., III (1975), An Examination of a Distribution of TAC CONTENDER Solutions, NMCSSC, TM 101-75.

Hartley, Dean S., III, et al. (1989), Sensitivity Analysis of the Joint Theater Level Simulation I, Martin Marietta Energy Systems, Inc., K/DSRD-70.

Hartley, Dean S., III, John D. Quillinan, and Kara L. Kruse (1990), Phase I Verification and Validation of SIMNET-T, Martin Marietta Energy Systems, Inc., K/DSRD-116.

Hartley, Dean S., III (1990), Historical Validation of an Attrition Model, Martin Marietta Energy Systems, Inc., K/DSRD-115.

Hartley, Dean S., III, Charles Radford, and Cathrine E. Snyder (1991), Evaluation of the Advanced Battle Simulation in WAREX 3-90, Martin Marietta Energy Systems, Inc., K/DSRD-597. 
APPENDIX: VERBATIM COMMENTS 


\section{APPENDIX: VERBATIM COMMENTS}

The verbatim comments are organized into seven sections. The first five sections are directly related to a taxonomy of the FTLM processes derived from the Future Theater Level Model (FTLM) Summary of Model Concept. These sections are Introduction, Architecture, $C^{3} I$, Maneuver, and Attrition. The sixth section deals with the need for congruence of the FTLM design and the MNS. The last section covers those issues that we determined to be Major Issues.

The portions of the sections in normal type face are guides to the process or issue under discussion. The portions in italics are our comments. The name of the individual making each comment is shown, flush right, at the end of each comment. Responses from the design team are shown in SMAII CAPS.

\section{GENERAL REMARKS}

1.0.1 My biggest problem with the math modeling in FTLM is with the justification for the various equations and models. The report on "Sensor Fusion Models $\Gamma$ " by $D$. P. Graver and P. A. Jacobs does give a reference.

Also, the report on "STOCWAR - Some Design and Implementation Concepts" by Sam Parry, 15 June 1992, does mention that some ideas were pulled from TAC Assessor and Combat Evaluation Model. Other then these few references, very little is said in any of the reports about justification of the models. In reading the reports, I get the "feeling" that what they are doing is defining some probability functions or distributions for certain variables and then applying probability theory to these functions to combine them. But how are they coming up with the probability functions?. Seems to me that they have "guessed" at some functions by looking at what mathematical functions behave in the way they think the variables should behave and then adding some "tweaking" parameters to the function to control its shape more closely. For example, on page 7 of the report "Physical Theater", 15 Mar 92, the equation:

$$
h(r)=1 /\left(1+\left(u_{e}^{*} r\right)^{* *} p_{c}\right)
$$

has the two user specified "tweaking" parameters $u_{e}$ and $p_{e}$ How does one specify these parameters? Do the parameters relate to any real work parameters that a commander can relate too. Or is this the same thing I've seen in other models where game players learn to think in terms of "what value do I give these artificial parameters so that the results of the game come out the way I think they should". To me, this kind of defeats the purpose of the simulation. If the results of the FTLM simulation come out wrong, you just go back and tweak some parameters till you get something reasonable when is actuality something is wrong with the modeling assumptions. It seams to me they have a parameter estimation problem but no real data for estimating the parameters or for confirming the form of the equations. 
This may be a reasonable approach for coming up with a theory, but is it the most reasonable way of coming up with a realistic simulation. Remember the work we did on Simnet-T. The model required certain parameters formulated in a certain way, but what we found was available was data formulated in a very different way. And it was a real guessing game trying to derive the needed data from what was available. My concern is that something of this sort will happen in the FTLM if the modeling is approached from a purely theoretical standpoint. Has anyone taken a look at what data is actually available and then tried to build a mathematical model around it?? Such a model may be less sophisticated but may have a real basis.

If not enough data is available for doing this, then maybe another approach would be feasible. The report on "Theater-Level Combat Modeling (Progress Report; Feb. 1992) by Graver, Jacobs, Marsh-Jones, and Parry advocates using the function:

$$
m_{i k}(t, *)=\left(B_{1}(i, t) / R_{1}(k ; t)\right)^{p} /\left(1+\left(B_{1}(i, t) / R_{1}(k ; t)\right)^{p}\right)
$$

to model the fraction of $B$ 's moving to node $k$ by $t+1$. This function "says that the fraction moved is an increasing function of $B$ 's perceived force ration to $R^{n}$. The "tweaking" parameter $p$ controls how sharply this function increases. How is $p$ determined? How about using a pool of commanders to generate data for doing the parameter estimation. That is, give each commander a number of scenarios with different values of $B_{l}, R_{l}$, etc and ask them what they would do. Then use this data to generate an estimate for $p$. If you can't get a good estimate, then maybe the form of the equation is wrong and it needs to be changed. Then when this is used in the FTLM simulation and the answers don't come out reasonable, then probably something is wrong with how the various equations were combined rather than with the parameter value. Kruse

1.0.2 As far as the equations they have used go, most of them are difficult to verify and appear to be guesses at the functional form with no justifications given. I'd like to know more about their justifications. I did see a few equations that don't seem right:

"Scoring by Attrition in Combat Models" by D. P. Gaver:

1) I think equations 3.4 and 3.7 should read $E[B(t+1) \mid B(t) R(t)]$ rather than $E[B(t+1) \mid R(t) B(t)]$ to mirror equation 3.3

2) Equation 3.7 should have $B(t+1)$ rather than $B(t-1)$. "Physical Theater", 15 Mar 92

1) Page 6 uses a Uniform distribution for estimates of the Red force by Blue. This doesn't seem very realistic to me. If the Blue's intelligence is very good, they should have a tighter distribution about the real value than if their intelligence is not so good.

Kruse

\subsubsection{ALGORITHMS, HEURISTICS, EQUATIONS, AND APHORISMS}

When an activity is well defined and there is a validated formula that describes it, that formula should be used. Under other circumstances, care must be taken. Concatenations

An activity may be modeled with an approximation based on little knowledge; however, such an approach should be avoided. For instance, assume a set of serial activities, each of which may be modeled with a validated formula, except for one in the middle. Using a guess on this activity places the model of the 
composite activity at this same low level of fidelity, despite the conditions for each of the other activities. It would be better to replace the whole composite with a single guess because it places better visibility on the problem and may have some accessible data to use in tuning the guess.

Excessively long chains of reasoning are to be avoided when possible, especially reasoning that requires extensive mathematical skills. Errors are less likely to be caught in the reasoning because there are fewer people who can follow the mathematics. Also, long chains of complex reasoning are more apt to be coded wrong and the error remain undiscovered.

Complexity

If you have what appears to be a very clever conceptual model and it is complex, recast it with an approximation. Check the two against each other and against the data. If at all possible, use the approximation. If you must use the complex formulation, explain it at great detail with copious examples. Assume your audience has had calculus, but only remembers it vaguely. If you can't do that, don't use the formulation.

If it seems desirable to decompose an activity for modeling, it is better to first discover the data available for testing a model of the activity. These data should drive the decomposition into modules, as well as the depth of the decomposition. It is better to have a demonstrable approximation to a process than to have a fine theory with no defendable connection to reality. This is true for two reasons: the error level of the approximation is more nearly computable and data to drive the approximation are more likely to be available.

Theories

Theories are nice; however, remember we don't really understand war. Your formulas stand as propositions to be proven, not by mathematics, but empirically. If there are no data to fully validate the proposition, it could well be false. Remember that a rifle that is calibrated and precise enough to have a three centimeter shot group at 1000 meters will be fired by a human. If your proposition is true given a set of circumstances that don't include a pertinent battlefield parameter, it is not only not useful, it may be dangerously wrong. Data

You must start with the data because the model user will use data. If your model requires data that don't exist, how will the user cope? The user must either invent the data or not use the model. You must start with the data because that is all you have to test your model. A good approximation with a known error level is better than an finer detail model with no information on its accuracy.

Modeling

What do you do when there are no data, yet you must create a model? Start with the belief that your model will be wrong. Your goal is to minimize the significance of the error. A simpler model will be easier to replace if a better one is ever found. A simpler model is easier to describe. A simpler model will have fewer tuning parameters and the meaning of the parameters will be easier to describe.

Start with boundary conditions. You may be able to get strong conditions on your model. Next, consider all possible parameters. Look for data, including expert opinion on the nature of the impact and crossed-term effects of the 
parameters. Get rid of any parameter that appears to have less than a $10 \%$ effect on the model. Look for reasonable random distributions to substitute for missing variables. Write an explanation that shows why the model was chosen and shows how each tuning parameter should be chosen, what the bases for the decisions are, and how each drives the model. Be very, very clear. A random result that is replicated many times is preferable to a deterministic result of unknown value.

Hartley

\subsection{PROBLEMS WITH CURRENT THEATER-LEVEL MODELS}

1.1.0.1 Youngren states that current theater-level models fail to represent the uncertainty in predicting outcome. That's probably because, at aggregated levels, no one knows how to introduce uncertainly which was aggregated out at the lower levels. Interesting.

Martellaro

DISTRIBUTIONS ARE USED TO SUBSTTTUTE FOR THE LOSS OF DATA PRODUCED BY AGGREGATION

1.1.1 Modeling Imperatives

1.1.1.1 Many input values are unknown and unknowable

1.1.1.1.1

Not all probability estimates, especially in air-to-air combat should be generated by the model and then aggregated. They should be input from the field. Experience has shown that values calculated from engineering data, using standard models of acquisition do not match field data for the system as a whole.

Martellaro

1.1.1.1.2 They seem to be basically saying that they see the problem and they know it exists and they are just going to treat it by letting everything be variable instead of fixed. I don't see any discussion about where they will be getting the values they do use for various parameters and probabilities they are using in algorithms. And what is their starting point?. Are they starting with a model whose philosophy they like and then trying to find data to fit it or are they looking at available data and trying to design a model around it? Kruse IT IS A COMBINATION OF THE TWO POSSIBILITIES.

1.1.1.2 Operational issues have more effect on outcomes than tactical issues 1.1.1.2.1

I believe this, but is it faith or fact?

Hartley

REFERENCE WILL BE GIVEN.

\section{ARCHITECTURE}

2.0.1 Figure is misleading and should be drawn differently. instead of showing the Analytic Structure and Environment models separately, there should be a large box drawn around the $C^{3} I$, Maneuver, Attrition, and Logistics models. this box would then represent the Analytic Structure and Environment models since all of the processes occur within an environment and must be developed within an overall analytic structure.

Turley 
2.0.2 With the FTLM there is an opportunity to model more than two forces. If each side is represented as an object, there should be no theoretical reason that $n$ sides cannot be represented. (Practical issues such as execution time may restrict the size of $n$.) This permits situations where there is an active population, white force, which may clog the transit nodes and be attrited in battles and air strikes. It also permits modeling imperfect alliances. The alliances can be imperfect in their perception of allied positions, COAs, etc. and be imperfect in their shared goals. It also permits resigning from the conflict by $a$ side (or switching alliances). In a multipolar world, this capability may be required. Hartley

2.0.3 Accounting for civilian side loyalties: rules could be created that represent support for a combatant side, based on proximity to combatant controlled nodes, time since last occupancy, aggressiveness of recruiting, attrition at the hands of a combatant, etc.

Hartley

2.0.4 Bottom line: develop a firm concept of what processes are properly stochastic at this level. I'd like to see a chart outlining each process and why it is a candidate for variability. When that's done, we can all look at it and put it in perspective with respect to previous models versus theater level planning concepts.

Martellaro

2.0.5 Is TAC Thunder being used in its present form, that is, are they doing a tie into TAC Thunder and doing communication between the two models, or are they going to modify the TAC Thunder source code to fit their needs, or are they just going to use TAC Thunder as a conceptual starting point and write all their own code?

Kruse

ONLY SOME PARTS OF TAC THUNDER LOGIC WILL BE USED. THERE ARE PROBLEMS WITH MANY PARTS OF THAT MODEL. THE LOGIC WILL BE PART OF FTLM.

2.0.6VIC's grid cell geometry and it's avenues of approach methodology for ground maneuver make it capable of modeling surprise and military objectives other than FEBA movement. Any lessons?

Hartley

2.0.7 Experience with CASTFOREM has shown that multiple replications can be performed, given analyst and organizational discipline.

Hartley

2.0.8 Eagle should have areas of commonality; however, its execution (as described in the documentation) is so poor that there is little hope of learning anything from it.

Hartley

2.0.9 JTLS allows multiple sides. There is no reason for FTLM to fail to allow multiple sides also.

Hartley

2.0.10 Several mistakes in programming structure were made with JTLS because of worries about the wrong computing bottleneck. Discussions with Rolands \& Assoc. about such issues might help prevent similar mistakes in FTLM.

Hartley

2.1 Terrain Resolution

2.1.0.1 One problem with the design of the FTLM is the problem of indicating the territory that is held by each side. As long as a physical node or a transit node is occupied by a unit of a side or by a unit from each side, the ownership is clear. In a totally non-linear campaign this may be adequate and correct; however, in a conventional or semi-conventional 
campaign, some territory may be correctly regarded as secure even though no atom sized unit occupies a node. FTLM could use some concepts from cellular automata to rectify this situation. Each node (physical and transit) could have an ownership attribute. This attribute is set by proximity to units and to other nodes and by history by some rule set. For example, if a node is occupied by units of only one side, it is owned by that side. If occupied by units of multiple sides, it is in contention. If all neighboring nodes are owned by one side and it is unoccupied, then it is owned by that side. If some neighboring nodes are owned by one side and others by another side, then its ownership attribute decays over time toward the side owning the most (or most modified by closeness) neighbors. This attribute should be evaluated in deciding paths taken by units. Hartley

2.1.1 The ground network

2.1.1.1 Need to include algorithms and methods of defining network to correctly model everything (like in Ground Maneuver paper)

Hartley

2.1.1.2 How are physical node capacities handled (multiple arcs meet in a node of lower capacity=bottleneck and difficulties should ensue)? Hartley

2.1.1.3 User input: Document says "Starting node with planned departure time (this will be the initial perceived location)." Does this imply that a unit might not know its own actual location or just that its $H Q$ might not know each of its units' locations?

2.1.1.4 How is planned arival time used?

Kruse

2.1.2 The air network

2.1.2.1 Fig 3 shows arc crossings that are not nodes. This isn't consistent. Does it cause problems (aircraft can pass with no interaction)?

Hartley

AIR INTERACTIONS WILL BE TESTED BY RANGE CIRCLES, OBVIATING THIS PROBLEM.

2.1.3 Connecting the air and ground networks

2.1.3.1 How is the overlay of the air network on the ground network used? What if the arc a transit node is on is partly in and partly out of the Reconnaissance template? Can a ground node or transit node be linked to more than one air node?

Kruse

2.1.3.2 Be careful how the air and ground network grids are setup. Make the air network much finer and capable of being co-located with the ground network. Otherwise there may be technical problems later when trying to interface ground units with air units (Air Defense -> aircraft) or Close Air Support (Air -> ground)

Martellaro

2.1.4 The logistics network

2.1.4.1 What does MSR network (the logistics network) stand for? Hartley

2.1.4.2 You say the MSR network is a subset of the ground maneuver network. Why not a super set with extra roads too small for brigade maneuver or an intersecting set with extra roads but lacking cross country arcs?

Hartley 
2.2 Unit Resolution

2.2.0.1 Will there be a need to answer questions about the difference that a weapon system change makes ( $F-15$ vs $F-22, M 1 A l$ vs $M 1 A 2)$ ? If so, this will have an impact on resolution issues. Hartley RESOLUTION WILL GENERALLY NOT SUPPORT WEAPON SYSTEM LEVEL QUESTIONS.

2.2.0.2 In the Units paper (Draft 27 July 92) you discuss attributes and in the Strength paragraph mention pointers to lists of attributes. You should consult with Ed Kelleher of Rolands concerning pros and cons of structures for unit attributes. He has mentioned to me some errors he has made in the past in this area and his thoughts since then. Hartley

3. THE C $\mathrm{T}^{3} \mathrm{MODEL}$

3.0.1 PERCEPTION AND UNDERSTANDING IN FTLM

On the real-world battlefield, perception is achieved by a variety of means. Soldiers see (hear, feel or smell) things directly or receive data from mechanical sensors. In either case, what they sense must be interpreted before being understood (whether correctly or incorrectly). In the FTLM, there are no individual soldiers, whether privates at the front lines, staff intelligence analysts, or generals in the theater command post. There are, however, three possible levels of command, exemplified by the decisions made for each brigade, (potentially) node-level decisions, and theater level decisions.

These FTLM decisions, like the real-world decisions, should be informed by an understanding of the situation, not raw sensory data. Part of the need for the FTLM is to have a model that produces a spread of likely results of combat scenarios and one of the key assumptions is that command decisions are an important source of real-world variability. We know that some of this variability derives from differences in human decision making; however, we also know that some of it derives from the fact that the information on which the decisions are based is inaccurate and subject to variation.

Part of the architecture of the FTLM is based on this variation of information about the state of the (model) world. We don't have a ready-made statistical description of this variation. For example, we can't say that a commander from country $y$, on the defense, in hilly terrain, facing a brigade from country $x$, will perceive his enemy as a company with $5 \%$ probability, as a battalion with $20 \%$ probability, as a brigade with $40 \%$ probability, as two brigades with $30 \%$ probability, and as a division with 5\% probability. (In addition, the description would also include something like tank-heavy or not and likelihood of air support and amount of artillery, splitting the categories.) It is probable that no more resolution than this is required for FTLM. However, in an effort to justify such a description, more detail has been suggested.

The question is, "how much detail is required and is it supportable?" The description above is approximate and needs to be confirmed; however, the concept is that the command decision is based (in part) on an understanding of enemy force size and capabilities. (The example above suggests another distribution, that is the commander's view of the likelihood of other sizes for the enemy, given his base estimate.) Because of the FTLM architecture of replicating each run, different methods of generating the description above 
should be regarded as equivalent if the probabilities are within 10-15\% of each other. This equivalence should affect the detail required. (The understanding of the enemy's intentions [another part of the basis of the command decision] is similarly arrived at using the perception of positions and changes in position of enemy forces over time.)

The supportability part of the question involves data availability, data quantities, and model run time. We have data on sensor capabilities at the engineering level. Based on some knowledge of the TACSIM model, an extremely large, highly classified intelligence model, I suspect that building up from the engineering level of data to the level required for the FTLM would be unsupportable.

The approach of paragraph three either averages all reasonable actions to obtain information or includes each as a specific part of the case. That latter situation would be very clumsy and liable to error in enumeration. It appears that the FTLM should include the allocation decisions for intelligence gathering of some sort. This intelligence gathering will have a variable level of success. However, the interpretation of the intelligence will also have variable accuracy. In fact, an incorrect intelligence report can be incorrectly assessed to give the correct answer. I don't think there exists an algorithm that will "correctly" fuse sensor reports, no matter how well they are modeled.

I would ask the intelligence community if it could and would answer a set of questions such as the following:

Given a set of sensor packages (or appropriate terminology), given a general force description to be looked for (the enemy), for each terrain type, for each actual occupancy (empty, civilians, logistics movement, squad, company, etc.),

if sensor package $a$ is used (normal procedures), what probabilities would you associate with reporting each possible occupancy state? (This is a semi-fused result, that is, you would actually combine this with other reports to produce an estimate; however, assume for this part that the information is not wildly at variance with previous conceptions.)

If the answer from the intelligence community is "yes," then I would decompose the model no further. The Bayesian methodology for combining past perceptions with new perceptions is mathematically adequate, understood by many, and simple enough to explain to the rest. If the answer is "no," then I would ask them to describe a set of questions they could and would answer. Each level deeper requires another level of heuristic, each of which adds complexity, possible error, and sustainability problems. If it gets too deep, I would build a preprocessor to test the possibility of combining states that are equivalent in result. If the number of states that can be combined is large enough, a table look up in FTLM will be more efficient and the separation of the problems will be easier to explain.

Finally, the proper approach to perception and understanding in FTLM depends on what data are available.

Hartley

3.0.2 VIC is deterministic; however, it was specifically designed to include $C^{3} I$. Any lessons learned?

Hartley 
3.1 Planning

3.1.0.1 It would be worthwhile to examine how VIC approaches the COA planning problem and what people have to say about it. Hartley

3.1.0.2 CASTFOREM also demonstrates the need for intelligent COA modification and testing. If (as was shown in CASTFOREM and Janus studies) a new system is tested without accounting for differences in tactics, the full value of the system (or its problems) may be missed.

3.1.1 The operational concept

Hartley

3.1.1.1 At end of footnote 11: also don't know which is best and which is worst case - might set out to define each and not succeed. There might be something worse than worst case and better than best case. Hartley

3.1.1.2 Does the "enemy perception about our operational concept" relate to Western values? (As an extreme example, how about the value of life?) Are these values so inbred into our thinking that we are predictable despite a system that "seems" to offer a spectrum of COAs? Relates to the technique Grandmasters used to defeat the first generation of Chess programs that threatened them. About 1988-9, mainframe chess programs started playing at the 2200-2300 level. Grandmasters soon discovered the weaknesses of the programs and purposely led the chess program into these areas. Likewise, in any "system" that has built-in constraints, the enemy will tend to discover those constraints and exploit them.

Another example: $A 15$ year old Vietnamese girl is no match for a helicopter full of Marines, right? - until she smiles sweetly, approaches, and then tosses a hand grenade under the seat.

Another example: the Gulf War - when the offshore pump was opened and sent a huge oil slick towards the Saudi de-salinization plants. That's a "crime" that we would never consider, but which the Iraqi mentality seemed able to justify.

Another example: Japanese wargaming predicted that after the attack on Pearl Harbor, the U.S. would surrender. This was a military assessment, but it was based on the underlying principles of their culture. Hence it was a flawed decision.

I'd like to see a discussion of what assumptions or constraints will be made - both for us and for an opponent. We may want to compare those to those items selected for variable inputs and assess their relative importance. All courses of action the enemy might take should be surfaced for consideration, even if we would not consider them ourselves. Hence, the model may need to be asymmetric. Martellaro

3.1.2 Defining an operational course of action within FTLM

3.1.2.1 The examples in each of the sections below are presented as instances, not all inclusive; however, we might want to add some to make sure they aren't forgotten. look at other models and any things we think of ourselves.

Hartley

3.1.3 Establishing operational concepts under uncertainty

3.1.3.1 Aren't timing and speed of progress parts of COA? Can you deceive about either or both? Hartley 
3.1.3.2 Are deceptions intentional shifts from proper $C O A$ to some other possible $C O A$, or just fogging the issue, or are both modeled? Hartley INTENTIONAI DECEPTIONS BY SHIFTS MUST BE PART OF HUMAN SETUP OF COAS.

3.1.3.3 Document says "The model rule sets, as well as actions and values scripted by the analyst, will cause the forces to operate in various ways according to the relative likelihoods of the perceived COAs. Because the perception is based on stochastic processes ...". The perception is stochastic, but is the response to that perception stochastic or deterministic. That is, is there some fuzziness built into the outcome of applying the rule set, independent of the fuzziness of input parameters such as perception? This could account for "intuition" and other such intangibles not directly modeled.

Kruse

FIRST VERSION WILL USE DETERMINISTIC RESPONSES.

3.1.3.4 Document says, "the analyst can either expand the rule set, insert one or more external events to force particular decisions or events to occur, or stop the model, make manual changes to the data, and restart it". Does this mean that expansions to the rule set and insertion of external events is made on the fly while the model is running? Is this analyst a systems manager type or just a player type? Is there one for each side? More than one per side? I don't get a good feel from the specification what the nature of any "interaction" with the model is.

Kruse NO CHANGES DURING REPLICATIONS. ANALYST SETS UP BOTH SIDES FAIRLY AND MAKES TEST RUNS TO SEE IF ANYTHING WAS FORGOTTEN. CHANGES ARE MADE, IF NECESSARY, INCLUDING FORCE RULES.

3.2 Reconnaissance

3.2.0.1 Classification of objects as military may overlook key entities in today's (and tomorrow's) scenarios. e.g. Somalia - the object and objective may be a refugee camp, food distribution station, or hospital. Counter-narcotics Operations - objectives may be crops, processing laboratories, or civilian transport. Disaster Relief - there may be no military (or even human) enemy.

Packard FTLM IS NOT AIMED AT THIS LEVEL NOW. IT IS AIMED AT MRCS AND MAY OR MAY NOT HAVE APPLICATIONS IN THESE AREAS.

3.2.0.2 FTLM needs to allow multiple sides. This permits modeling of shaky coalitions with differing objectives and civilian populations that can suffer attrition and might shift loyalties. This will require various kinds of objects to be detected by recon.

3.2.1 Reconnaissance Operating Areas

Hartley

3.2.1.0.1

As I understand it, each reconnaissance type has its own template type and their can be numerous templates of each type. Do the various templates of a particular type belong to, i.e., are they assigned to, a particular reconnaissance asset or to the reconnaissance type? Can two reconnaissance assets of the same type share 
a template either at the same time or at different times?

Kruse

3.2.1.0.2 A template will cover or not cover a physical node; however, in general it will cover only part of a transit node. How will this be modeled? Hartley THIS IS UNDER DISCUSSION AND NOT DECIDED.

3.2.1.1 Scheduling times of detection

3.2.1.1.1 Document says "...modeled with periodic detection opportunities at a small delta $t^{\prime \prime}$. Does this mean that their will be times when the reconnaissance assets which provide continuous observation will not be able to detect?

Kruse

THE DELTA T REFERS TO CYCLICAL UPDATE. SINCE EVENT PROCESSING IS USED, THERE IS NO IN BETWEEN TIMES.

3.3 Fusion

3.3.0.1 What if FTLM fusion is better (or worse) than real life fusion process?

Hartley

3.3.0.2 Fusing recent perceptions and then updating perception database may yield different results from incremental fusion of each perception into database. Both processes probably occur in real life to some extent. How is this to be handled?

Hartley UNDER DISCUSSION.

3.3.0.3 As I remember, there are other algorithms for combining probabilities besides Bayesian and derivatives of Bayesian that are used in Expert Systems. Have any of these been considered? Kruse WAS CONSIDERED; BUT PEOPLE INVOLVED ARE BAYESIANS.

3.3.0.4 VIC models explicit sensor data collection and fusion using Kalman filtering. The data are used to support production of current target lists and a perceived situation. Any lessons? Hartley

3.4 Perception

3.4.0.1 It would be valuable to look at how VIC handles perception, looking at pros and cons.

Hartley

3.4.0.2 Perception should include orientation (Where is the combat power focused?) and subordination (Where is the combat support element? Where are the alternates?).

Packard

3.4.0.3 The need for logistics presents the opportunity to explain the perception of things that aren't there, i.e., tanks at nodes where there are really supply trucks or civilian trucks.

Hartley

\subsection{Decision}

3.5.0.1 Is the model run interactively at all or is the only interaction when the analyst interrupts the game to modify the scenario or rule set? Kruse THE LATTER (HOWEVER, THERE MAY BE AN INTERACTIVE VERSION. 
3.5.1 Decisions to be made by the operational commander

3.5.1.1 How about decisions to deceive enemy?

Hartley

3.5.1.2 Decision by higher commander should include camouflage, concealment, and detection (CCD) measures as actions that a unit may need to participate in to avoid overhead detection. Turley DON'T KNOW, IS A RESOLUTION ISSUE.

3.5.2 Missions

3.5.2.1 The Assignments for Ground Maneuver Forces assume conventional, traditional military operations. Humanitarian relief, emergency reaction, counter-narc are overlooked. NEED A REQUIREMENTS INTERPRETATION HERE -- THE MNS Para 3 DISCUSSION Says, "Changes in the world and changes in operational doctrine require a different representation of joint force employment, explicitly incorporating the uncertainties in the use of relatively smaller forces in a less densely populated theater." How important are the humanitarian relief, emergency reaction, counter-narc missions? Is brigade a low enough level of resolution to satisfy the MNS?

Packard

SMALL IN THIS CASE MEANS "NOT 8-10 CORPS," IN OTHER WORDS AN MRC.

3.5.2.2 Missions should include such forces as amphibious operations, special operations, and paratrooper operations. Turley WILL INCLUDE SOME OF THESE DEPENDING ON RESOLUTION (SOME FORCES WILL JUST APPEAR WHERE NEEDED).

3.5.3 Assignments for ground maneuver forces

3.5.3.1 How is "1. Occupy a node not presently controlled by own forces" different from "2. Occupy a node presently controlled by own forces". The two descriptions look identical to me.

Kruse TYPING ERROR, NEEDS CHANGE.

3.5.3.2 Is it a reasonable assumption that defenses occur only at physical nodes and delaying actions occur only at transit nodes?

Kruse

3.5.3.3 FTLM will have a play ahead (internal wargaming the situation) feature in the ground game. This is analogous to the kind of thing done in the air game of many models, that is, compute the best path, etc., based on probable outcomes. This has been done in air games because it is relatively straight forward to talk about single probabilities of kill (pKs) for the various threats to an aircraft. It is more complex on the ground. Two separate, but linked issues arise: what attrition model will be used by FTLM and how does a commander estimate the situation. Ignoring the commander's estimate for a minute, the look ahead attrition model used in FTLM should be related to the actual attrition calculations to be performed. In this way, the model won't pick choices that are dumb with respect to how it is going to evaluate the choices. (The basis for the choices, i.e., incorrect perception, may still lead to poor choices, but that's life.) On the other hand, if real commanders use (possibly incorrect) rules of thumb, regardless of the actual attrition mechanisms in war, what should be modeled?

Hartley

3.5.3.4 In planning the attack and choosing possible avenues of attack, it may be that the commander will choose the one with the greatest opportunity 
for surprise. (This is in opposition to the methodology described in Schmidt's thesis, in which each COA is examined for attrition results, with a modifier for surprise.

Hartley

3.6 Communication, Electronic Warfare, and Deception

3.6.1 Communication in FTLM

3.6.1.0.1

Can you say the impact of communications lies in the impact on decisions?

Hartley

3.6.1.1 Degrade the ability of units to communicate with the operational headquarters

3.6.1.1.1

You say it's possible to summarize detailed communications models. Is that really so? Who is going to do it? How? Hartley

3.6.1.1.2 VIC models explicit communications networks with loading, delay and priorities. Any lessons? Hartley

3.6.1.2 Degrade the ability of the operational headquarters to receive and process intelligence

3.6.1.2.1 You say that operational headquarters is assumed to be physically in the rear. In a non-linear battle, where is the rear? Is this assumption really required for what you say next?

Hartley

PHYSICAL LOCATION IS NOT THE REAL POINT OF THE DISCUSSION. THE PROBLEM IS THAT A SINGLE POINT WILL BE ASSIGNED FOR THE LOCATION OF THINGS THAT ARE REALLY SPREAD OUT OVER A LARGE AREA. THIS MEANS THAT A SINGLE BOMB WOULD NOT REALLY DAMAGE EVERYTHING. ARTIFICIAL HARDNESS MAY BE REQUIRED.

3.6.1.3 Degrade the ability of the operational headquarters to command and control forces

3.6.1.3.1 The figure shown on p.26 (Summ, Pt 1)is not labeled and needs to be for clarification (perhaps it is the perception database updating process). Also, the descriptions for transmission delay $T 12$ and T13 are identical. Should they be? Turley

3.6.2 Modeling communications degradation 3.6.2.0.1 Communications degradation figure shows baxes adding
$T_{12}$ and $T_{13}$ to delay but does not distinguish them.

Hartley

3.6.2.1 Affecting the quantity of communications

3.6.2.1.1 If a queue gets too big, there may be purposeful or random deletions (or selections to accept) queue members. Will this be modeled? TOO SMALL FOR FTLM RESOLUTION.

Hartley

3.6.2.2 Affecting the timeliness of communications

3.6.2.2.1 Communications timeliness should reflect the changing scenario. Lead elements into a theater have very limited communications unless the scenario is relatively 
benign to allow establishment of a substantial communications infrastructure. Field exercises usually ignore this fact by sending in communications (and other support) assets as much as a month ahead of the operators and conducting a COMMEX, so that communications will not degrade the FTX. Communications adequacy is changing with the introduction of each new or modified information system. Communications loads vary with the situation. "When the action starts, everybody wants to talk at once."

Packard

3.6.2.2.2 Document says "we can approximate the base case with a time $t_{d}=0$ and focus on times $t_{d}$ greater than the time resolution of information processing to reflect the effect of communications degradation"? Where does the value of "time resolution of information processing" come from. Shouldn't the base case be for $t_{d}=$ time resolution of information processing? Kruse

3.6.3 Modeling Electronic Warfare (EW)

3.6.3.0.1 How localized is EW? The mesh of the networks, air and ground, will impact this. The localization will drive the size of sigma. How much of the info that is processed is impacted by EW? I.e., to what does the sigma apply? (Improper sizing of meshes can make it difficult to separate what is included or include what should be included but is in a different node). Hartley PROBABLY WILL NOT DO EW ON NODE BASIS, BUT ON RANGE BASIS.

3.6.4 Deception and communications

3.6.4.1 Some reference to use of commercial news media for both intelligence and deception might be appropriate.

Packard

3.6.4.2 Operational Deception didn't cover some of the more common techniques such as using just-broken codes or codes suspected to have been compromised, false news releases from the local friendly forces, or supplying true but misleading information to news organizations, or appearing to take as face value and act on enemy propaganda and misleading information (but not actually doing so.) I think these are important at the theater level.

Martellaro

\section{MANEUVER}

4.1 Ground Maneuver

4.1.0.1 What about naval and riverine operations?

Hartley

NO NAVAL VS NAVAL OPERATIONS AND RIVERINE IS BELOW LEVEL OF RESOLUTION. 
4.1.1 The ground nodes

4.1.1.1 Logic for serial traversal would allow infiltration and pause to collect forces, etc.

Hartley

4.1.1.2 What about islands?

Hartley

4.1.1.3 What about using fuzzy logic for node suitability for enemy missions?

Hartley

4.1.1.4 Assume that multiple arcs will be required to represent transit of varied terrain, varied mode of travel (mounted vs dismounted), day vs night, forced march vs cautious advance, single route vs parallel routes. Friendly and enemy units traversing intersecting transient arcs (over which the average travel times are equal) might be represented as having a meeting engagement when the actual travel time over different segments of the transient arc might cause them to not encounter one another. Pages 2-3 resolves this adequately.

Packard

4.1.1.5 Are node characteristics variable. Can engineers alter open terrain to rough? Can supplies at a node change? Can node type (mission value) change?

Packard TO BE DETERMINED.

4.1.1.6 Can a transit node become a physical node during the game, either by analyst intervention or by model logic?

Kruse No.

4.1.2 Activities that can occur at physical nodes

4.1.2.1 Can the force located first at a node be the attacker?

Kruse YES.

4.1.3 Activities that can occur at transit nodes

4.1.3.1 What about observation and attack by armed reconnaissance missions? Hartley

NOT CURRENT US MISSION TYPE - HOW ABOUT ENEMY OR FUTURE CHANGES?

4.1.3.2 What about effect of obstacles of concentrating $a$ delayed force in $a$ killing zone - higher attrition?

Hartley

THINK ABOUT.

4.1.3.3 Might want prob $<=1$ for meeting engagements to include cases where arcs are really ill-defined because terrain allows many choices (desert) and forces might miss each other or might not. (This is a reason to not simply define lots of alternate arcs, to allow a force to detect the other and move to attack.)

Hartley NOT SURE. HAVE CONSIDERED VERY DENSE NODE NETWORK (LIKE AIR NETWORK) FOR THESE SITUATIONS.

4.1.3.4 How about meeting engagements by forces moving in same direction, but one faster than other (modeling attack from rear)?

Hartley

4.1.3.5 The assumption that a meeting engagement will occur may not always be valid. Are there provisions for special operations forces which move along the same transient arc, but avoid detection (infiltration). Are there provisions for special operations forces which are in stay behind mode? Pg 8 para b. resolves. Resolution of model is brigade and higher.

Packard 
4.1.3.6 Seems to contradict pg 7, para 4 by permitting passage through transient node without action, however, this helps resolve my concern above.

Packard

4.1.3.7 Special operations forces should be considered here. This type of unit can travel undetected along the same transient arc.

Turley DIRECT INSERTION OF FORCES.

4.1.3.8 Document says "Specifically, the following activities can occur at physical nodes: 1. Deep attack strikes. Any physical node ... "Is this a typo and they mean transit nodes? Kruse TYPO.

4.1.3.9 Can a meeting engagement occur if both forces are moving in the same direction and the last one is moving faster and catches up? Kruse

4.1.3.10 If I understand correctly, $a C^{3} I$ asset moving along an arc would be a ground unit with $C^{3} I$ capabilities. Is a "counter-C $C^{3}$ I attack" the same as an attack on any ground unit, but that unit just happens to have $C^{3} I$ capabilities, or is there something special about counter- $\mathrm{C}^{3} I$ attacks? Kruse EW JAMMERS, ETC.

4.1.3.11 Document says "This represents reconnaissance directed at a specific area along the arc that may be occupied by the unit." An arc is the path between two physical nodes represented by one transit node. Is the resolution such that it can resolve specific areas along the arc? How is this done when the arc is represented by one transit node?

Kruse CONCEPT IS NOT COMPLETE YET. THEY ARE CONSIDERING

4.1.4 Maneuver decisions SOME KIND OF SUB-NODE.

\subsubsection{Movement to an objective}

Can the user change paths or define paths during the course of the game? When does a route get dynamically replanned?

Kruse

PATH - YES; NETWORK - NO.

4.1.4.2 Splitting the force among two or more paths

4.1.4.2.1 What about splitting force for serial traversal of narrow path?

Hartley

FORCES MUST BE PREDEFINED AS TO HOW THEY SPLIT (UNLIKE SOME OF DOCUMENT REFERENCES). GENERALLY BRIGADE WILI BE LOWEST LEVEL OF SPLIT.

4.1.4.2.2 How about notional splitting (produced by delay between front and back arrival)? Hartley

4.1.4.2.3 When splitting forces, to what unit level? For parallel passage? For serial passage on same route? For separate missions?

Packard

4.1.4.2.4 Camouflage, concealment, and detection (CCD) measures should be included as actions that a unit may 
need to participate in to avoid overhead detection.

4.1.4.3 Reactions to problems encountered enroute

Turley

4.1.4.3.1 In delay situations may want to include different arrival times for different parts of a unit in combat assessment? Hartley

RESOLUTION MEANS THIS WILL BE HANDLED IN ADJUDICATION OF COMBAT ONLY.

4.1.4.3.2 The idea of penalizing a force for being late demands some discussion. One could argue that the force is discounted in combat effectiveness for not being at the objective and prepared for the next action, which seems to be the author's rationale. If there were no action planned immediately upon arrival, would the author then cause the force's combat effectiveness to return to full value? Another idea is that arriving on time or early requires speed which might reduce combat effectiveness through physical exhaustion, reduced control or vehicular accidents. Packard THE PENALTY IS ONLY IN ATTRITION CALCULATTON AS AN EFFECT OF LATENESS, IT ISN'T A SEPARATE PENALTY VARIABLE.

4.1.4.3.3 We assume the transit environmental characteristics for the close combat model would include degree of darkness and, if dark, quality of and competence with night vision equipment. Additionally, terrain should influence the percent of the attacked force which is exposed and can participate in the defense/counter attack.

Packard

4.1.4.3.4 Should there be an accompanying EW module to calculate the final strength after an engagement?Turley

4.1.5 Maneuver variables

4.1.5.0.1 Is there a time delay for other kinds of attack besides deep attack?

Kruse

4.1.5.1 Time delay due to encountering enemy action (or natural obstacles) 4.1.5.1.1 Is this the place to insert nuclear, biological \& chemical $(N B C)$ effects? Is this included in deep attack?

4.1.5.1.2 What is the justification for this algorithm? Packard

4.1.6 Terrain effects on maneuver

4.1.6.1 If an arc's terrain marginally supports passage by a unit, could that same terrain be less trafficable to the next unit. E.g. a heavy force crosses wet farmland or grassland, reducing the terrain to mud. A dismounted unit (friendly or enemy) attempts passage before the mud dries. The same unit attempts passage after the mud dries. Packard

4.1.6.2 What about NBC warfare? this would definitely effect ground maneuver. 
4.1.7 Environmental effects on maneuver

4.1.7.1 What about effects on morale?

Hartley

4.1.7.2 Some arcs may be usable (or at least favor use) by only one side (vehicle type, etc.)

4.1.8 CUTM-generated arcs for seasonal effects

Hartley

4.1.8.1 Will need info on CUTM to detect modeling implications of CUTM choices (e.g., what does it do for desert, where you can define paths going anywhere)?

4.1.8.2 What is CUTM?

Hartley

Kruse

CUTM IS AN AUTOMATED TERRAIN ANALYSIS TOOL. IT WILL BE REPLACED BY DEEM (DYNAMIC ENVIRONMENT EFFECTS MODEL) WHEN DEEM IS FINISHED.

4.1.9 Local and specific weather effects

4.1.9.1 Should the weather effects be generated from historical, meteorological files or taken as an "average" weather pattern for that season? Turley

4.1.10 Enemy or man-made alterations to the terrain

4.1.10.1 Assume that Enemy or man-made alterations to the terrain will include obstacles, minefields, urban rubble-ization. Packard

4.2 Air Maneuver

4.2.0.1 This section is well-written and well thought out. Perhaps the ground maneuver section should have the same amount of detail, i.e., equipment types and equipment type mission assignments; or is this already taken care of by the composition of the ground unit assigned? Are ground units "pre-packaged" for a mission or is it necessary to pick and choose from all the available assets (like the air mission packages)? I am showing my Amy ignorance.

Turley

4.2.0.2 The concept of using the Dijkstra algorithm for Air units using minimum cost, where the cost is related to the Air Defense threat is exactly correct. This very popular now in flight planning.

Martellaro

4.2.0.3 How is airspeed represented when nodes are gridded? This may affect mesh size.

WILL THINK ABOUT.

Hartley

4.2.1 Mission allocation

4.2.1.1 Missions

4.2.1.1.1

4.2.1.1.2

What about armed recon?

Hartley

Has the developer addressed the possibility of flights being reduced during or just prior to launch or are all requested flights assumed able to reach the rendezvous point if they are in the available aircraft list? Packard 4.2.1.1.3 Document says "Rotary wing aircraft $M A Y$ be represented as a strike system within the ground model; in this role, they are not considered in the air model of FTLM." Can rotary wing aircraft play other roles, and can any of the other roles be part of the air model? 
UNLIKE SOME MODELS, CAS WILL BE IN THE AIR MODULE AND TREATED AS A FORM OF STRIKE TO PREVENT DOUBLE COUNTING OF AIR POWER. IN GENERAL, HELICOPTERS ARE IN DIRECT SUPPORT OF BRIGADES AND WILL BE TREATED AS ORGANIC PARTS - LIKE 'FLYING TANKS'. HOWEVER, HELICOPTERS CAN BE USED AS CORPS OR THEATER RESOURCE AND WILL BE PLAYABLE AS PART OF AIR OPERATIONS. CARE WILL BE NEEDED TO SUBTRACT THEM FROM BRIGADES WHEN THIS HAPPENS TO PREVENT DOUBLE COUNTING.

4.2.1.1.4 If a certain number of aircraft are used for logistics, the air model can simply allocate that number as unavailable. If they are subject to attrition, a probability distribution can kill off some sometimes.

Hartley

4.2.1.2 Aircraft types

4.2.1.2.1

What about AC130s? may be needed for non-standard or non-European contingencies. Is this a problem?

Hartley

AC130S CAN BE PLAYED. THE LIST AS GIVEN WAS PRELIMINARY AND NOT EXCLUSIONARY.

4.2.1.2.2 Is this the right way to handle rotary winged aircraft? It will make decisions involving them difficult, perhaps?

Hartley

4.2.1.2.3 Are particular aircraft types to be played, e.g. F16s, or will there be notional aircraft, e.g. "tactical fighter?" Where will data for notional aircraft be obtained or how will it be derived? How much data will be required if real aircraft are played? How will munitions be modeled (same questions)? Hartley

4.2.1.2.4 One of the early papers suggests notional aircraft such as TF-CAS and TF and TF-INT, how about Wild Weasels? Hartley

4.2.1.2.5 The early paper suggests the possibility of having CAS as a ground forces weapon (I presume similar to JTLS). The impact of such a decision should be tested by trying both explicit CAS and implicit CAS. Some problems were observed in JTLS (perhaps because CAS could be produced both ways. Hartley

4.2.2 Create air action units (sorties)

4.2.2.1 Mission package

4.2.2.1.1 When creating an actual package, will there be provisions for aborting the creation because of lack of numbers or critical resources?

Hartley

4.2.3 In flight

4.2.3.1 How about effects of flight profile, nap of the earth, etc.? Speed over ground, vulnerability, detectability, direction of attack? Hartley 
4.2.3.2 In considering flight from base to rendezvous point, consider non-linear battlefield where enemy can be anywhere and Israel where Israel may control air, but enemy ground forces are real close.

Hartley

4.2.3.3 Playing entry comidors is strongly dependent on mesh size of air nodes!

Hartley

4.2.3.4 There is a problem with defining anti-air defenses only at nodes. If one side has a doctrine of anti-air integral to small forces, the density across the theater may be misrepresented, allowing too free access to air corridors. This is especially true for representing more conventional scenarios. FTLM should not be restricted to answering questions only when the theater looks nothing like Europe. The question arises of how best to represent the texture of the air defense threat in a 3-dimensional view (including varying vertical ranges).

Hartley

4.2.3.5 Too small a mesh might mean that some long range air-air weapons lose the advantage of shooting enemies at long distances (if play only shoot enemies in own node). Other considerations say use smaller mesh, may have to consider node plus ring of nodes or more. Hartley AIR AND ANTI-AIR WEAPONS WILL BE PLAYED WITH RANGES AND PERCENT COVERAGE OF RANGE CIRCLE INTERSECTING NODE SQUARE.

4.2.3.6 Pg 8. The introduction, "We begin modeling the ingress at a rendezvous point over friendly airspace," may not always reflect a valid assumption. While air superiority appears to be a given in most scenarios, there remains the possibility of mission packages being attacked before or while assembling. Packard THERE WILL BE MAJOR DIFFERENCES BETWEEN FTLM AND TAC THUNDER. THERE WILL BE NO FLOT AND SO NO GUARANTEED SAFE TERRITORY.

4.2.3.7 Pg 8. "This generic egress model..." in the discussion of Ingress, suggests that ingress and egress are treated identically. It seems that there are significant, although perhaps equally offsetting, differences between ingress and egress. During egress there is a substantially reduced element of surprise. The defenders are well aware of aggressor aircraft within their airspace. During ingress, while the aggressors enjoy greater surprise, the defender's sensors and weapons are more likely to be correctly oriented.

Packard

4.2.3.8 Chapter 2, page 2-3, paragraph 2.2.2, Air Mission Sequence. "Flights may originate at several bases and rendezvous at specific points. The flight group then crosses the FLOT, where combat losses may occur." The concept of a FLOT, behind which forces are safe is not necessarily valid for future conflicts. It assumes air superiority (probably valid), a "friendly" zone from which aircraft launch and rendezvous (not necessarily valid), and no opposing AA capability within that friendly zone (wishful thinking). This philosophy does not allow for loss of air assets due to enemy action at the forward operating base. CBAM or some similar model might rectify this apparent shortfall. Packard No FLOT. 
4.2.3.9 Chapter 10, page 10-7. The concept of a FLOT persists. page 10-13. The sanctity of the FLOT is reduced here with the possibility of the FLOT moving or of the base being damaged. My faith is restored.

4.3 Logistics Movement

Packard

4.3.0.1 This is good - it lends itself to modeling the humanitarian action.

Packard

4.3.0.2 The Situation \# 4 - Developer should be sure to link national assets correctly THINK COMBINED OPERATIONS. Logistics may not be interoperable among nations.

Packard

4.3.0.3 Some Suggested Approaches \#1 - not all logistics originate in CONUS. Remember combined and pre-positioned assets.

Packard

4.3.0.4 Some Suggested Approaches \# 2 - there are some extremes in port activity which developer should make a conscious decision to model or not model. One extreme is CHAOS - nothing can be identified, wrong stuff gets forwarded at worst time. Another extreme is perfection - the logisticians can rapidly find any asset and load, dispatch, and transport exactly what is needed in time to make decisions and execute operations with confidence.

Packard

4.3.0.5 Logistics Feasibility - be sure to get a real logistician 's opinion to off-set the operators tendency to shrug off the complexities. Things just don't get to the combat units in nice, evenly distributed packages. Example:: if half the convoy is food and half is ammo, the receiving unit is not half ready when all the food arrives - he is totally unready. Packard

4.3.0.6 Automated Decisions -Seems like this would be very helpful in initial force laydown. Rapid scenario setup seems to be a major goal - let the analyst place an element of a unit (say the forward shooters) and have the system apply a notional (non-terrain) spatial distribution, then adjust for terrain and adjacent units.

Packard

5. ATTRITION

5.0.1 Attrition may involve morale and experience (cf. training) that change over campaign Hartley

5.0.2 Where will the developer reflect uncertainty or change in the alignment of forces encountered. Armed neutrals, angry, armed civilians,or hostiles with whom contact is forbidden by rules of engagement?

Packard

5.0.3 "Attrition modeling is overworked." I very much agree. Martellaro

5.1 Air Attrition

5.1.0.1 When air units are returned to their respective bases, how are the losses going to be divided up - randomly, proportionally, or other? Kruse THIS HAS NOT BEEN ANSWERED YET. SHOULD THERE BE A ROLL OF THE DICE AT EACH AIR NODE, OR CARRY FORWARD THE EXPECTED SURVIVING A/C WITH A ROLL TO ROUND AT THE END? THERE WILL BE AN ADJUDICATION AT EACH AIR NODE OF SOME SORT. 
5.1.0.2 Chapter 12,page 12-3. It appears that attrition of friendly air is based on a "killed or unscathed" philosophy. Are there provisions for some aircraft to be damaged and

1) returned to base for future use

2) continue on mission with degraded capability

3) returned to base and aircraft lost, but crew saved

This is not particularly important in assessing the day's combat outcome, but may be relevant to a protracted conflict with limited air assets.

Packard

5.1.1 Air-to-air combat

5.1.1.1 Is the number of aircraft lost in each flight a stochastic variable?

5.1.2 Air defense modules

Hartley

5.1.2.1 Too large a mesh means that too many $A D A$ can engage too many aircraft, too small a mesh means that too few $A D A$ can engage too few aircraft; however, proper $A D A$ vs aircraft mesh may not be proper for air-air engagements. May have to have multi-node search. What about edge effects (aircraft or $A D A$ near edge of area and can't be shot at or shoot at near but unavailable enemies)? Is this important? How do you tell?

Hartley

WILL USE RANGE CIRCLES RATHER THAN NODE PARING FOR ADA.

5.1.2.2 Short range air defense (SHORAD) equipped forces by units too small to be explicitly represented in FTLM can be represented by a small $p K$ associated with each node and link based on proximity to combatant sides.

Hartley

5.2 Close Combat Attrition

5.2.0.1 $A C^{3} I$ question: suppose there are $2 R$ units and $1 B$ unit. Situation 1: the $R s$ have good $C^{3} I$ links, so decisions to break off or call for fires, etc., are coordinated single decisions. Situation 2: the Rs have bad $\mathrm{C}^{3} I$ links, so decisions are separate, based on each's estimate of situation. Are both situations handled?

Hartley

5.2.0.2 Heterogeneous Lanchester equations are very difficult to assess in practice. Most models that use them end up with very complex attrition coefficients that involve time, distance, allocation of fires, posture, etc. To varying degrees the factors and their mathematical insertion are justified verbally; however, it is not clear that the intended effects are accomplished.

Suppose the problem is to determine whether a replacement of tank $T 1$ by $80 \% T 1$ and $20 \% T 2$ is a good idea. One approach would be to run a model that allows two tank types. One run would have $100 \% \mathrm{~T} 1$ and no T2; a second run would have $80 \% \mathrm{~T} 1$ and $20 \% \mathrm{~T} 2$. However, it is not clear that every model is indifferent to splitting forces among weapon types. One should test $100 \% \mathrm{Tl}$ and no second tank types against $80 \% \mathrm{TI}$ and $20 \% \mathrm{TI}$ in the second tank position. The answers should be the same. Are they? 
Suppose the problem is sector attack: attacking the weak sector of a defended position, rather than the strong sector. The question here is whether in setting up the model to permit sector splitting actually produces the effect desired. Suppose you are attacking the weak side, the general effect should be to cause higher percent casualties to the part of the defense in the weak sector than would be the case on that part of the total defense if it were part of an undifferentiated defense or part of the strong sector. Also you should cause unanswered attrition against the rest of the force (for a while). The attacker should suffer fewer casualties than if attacking an undifferentiated defense or the strong sector. The complication of realistic heterogeneous equations may make this dependent on settings. (The results are not obvious.) Further, in the real world, this general effect may be screw-up-able (through conscious allocation-of-fire type decisions [not just through screwing up the attack]). These points need to be tested and decisions on what to model and how to model it taken consciously.

Hartley

5.2.0.3 But one danger in the stochastic output - ranging from the "no surprise" case to the "great surprise" case - is that the guidance will be broad and ill-defined. I worry about the wisdom of letting the user decide for himself whether the attack will be a surprise. Is this a useful approach when trying to introduce variability? Isn't it better to suppose that the enemy will not be taken by surprise, and if successful, simply move up the timetable? A sensitivity analysis needs to be done to determine whether making this assumption about the enemy's state is warranted. (This is a separate issue from the reality that taking the enemy by surprise is almost always good.) More exactly, it seems that the surprise/no-surprise is just one of a list of things that "seem like a good idea" to introduce without any sound justification for it being a variable factor. (See Architecture about making lists.) Martellaro USER DOESN'T DECIDE IF SURPRISE IS ACHIEVED.

5.2.0.4 Surprise can be a major factor on the battlefield. It can be achieved at the tactical, operational, and strategic levels. It can be achieved by either side (although it is more usually achieved by the attacker). FTLM will represent certain kinds of surprise explicitly, e.g., attack up an avenue of approach that the enemy considered unlikely, hence positioned the bulk of his forces elsewhere. Presumably (see next note) this will generate its reward directly by greater attrition than otherwise. However, there are other aspects of surprise that (apparently) will be represented in FTLM. These include both means and effects (such as greater attrition or breaking off a battle early). Some ways of representing surprise exist (Schmidt's thesis, Hartley's Oak Ridge Spreadsheet Battle Model [ORSBM]); however, care should be taken to prevent double counting the effects while ensuring that these other effects are represented.

Hartley

5.2.0.5 In the heterogeneous Lanchester attrition model that is proposed as one of the alternatives for attrition, the complexity will require detailed testing 
against certain flaws. One of these is an imperfect implementation of attacks to the weak side. Unless other factors dictate otherwise, an attack to the weak side should generate greater success than an attack to the strong side. Representing the defender as occupying subnodes which are engaged differentially is one approach. However, this approach has dangers. For instance, suppose the attacker has three brigades and the defender has four brigades at the node, one on the weak side, two on the strong side, and one in reserve. Note that direct calculation of a strong side attack shows three brigades attacking two brigades, which might give a win for the attacker when that is improper. This could be a result of mixed resolution, for the attacker (perhaps) should be represented as sub-setted with two brigades up and one brigade back.

Hartley

5.2.0.6 FTLM must represent the propensity of a defender to counterattack, given the opportunity.

Hartley

5.2.1 Determine forces engaged

5.2.1.1 How are uncoordinated groups of forces and partial forces against multiple opponents modeled?

Hartley

5.2.1.2 If a new force arrives at a node in the middle of an engagement, do you call an end to engagement and start new engagement with new total forces? In some cases this is the proper answer.

Hartley

5.2.1.3 How are indirect fires from other places handled in battles (considering shift of forces within a node)?

Hartley

5.2.1.4 The assumption that all forces in a transit node will be involved is bad news for modeling ambushes. Usually the ambusher only engages a part of the force (part of success story), then escapes. This is part of reason to use small capacity (narrow) but long arcs that extend the attackee. It might be necessary to model these as a sequence of transit nodes with serial splitting of force passing through. Can CUTM handle this with automatic chopping?

Hartley

5.2.1.5 The effect on morale and effectiveness of an ambush with locally heavy casualties is different from the effect of the same number of casualties spread throughout a brigade.

Hartley

5.2.2 Determine force postures

5.2.2.1 In determining force posture for computation of attrition, the developers should consider the impact of a force operating contrary to US (or any accepted) doctrine. For example, doctrine defines the narrowest acceptable movement comidor. A force might choose to transit a much narrower corridor, either for expedience or due to lack of experience/training. This might result in a force posture which permits an extremely small percentage of combat power applicable to an enemy encountered enroute. Such non-doctrinal occurrences seem more likely in "the new world."

Packard

5.2.3 Close combat attrition object

5.2.3.1 In Footnote 8: does the unit "know" its own numbers (for breakpoint calculations), or does it have a "perception" of these that may be wrong?

Hartley 
5.2.3.2 In Footnote 10: will need a modification of ORSBM for expected arrival of reinforcements: suppose battle time is going to be 2.5 days and reinforcements will arrive in 1.1 days. Need to adjust attrition (and morale, etc.) for 1.1 days of fighting, stop the engagement and compute new one for new forces and new situation.

Hartley

\subsection{Strike Attrition}

5.3.0.1 The description of the TAC THUNDER air-ground attacks in one of the early papers appears to be a combination of calculated probabilities and stochastic processing (plus some expected values [cookie cutter weapon effects radius]). Combining these makes the algorithms anything but transparent. Questions of efficiency also arise. At the very least, a straightforward walk-through type explanation is needed. Hartley

5.3.0.2 I didn't see anything I disagreed with. One of the variable factors not mentioned is fratricide. (Mostly air-to-ground. Doesn't happen much in air-to-air.)

Martellaro

5.3.1 Target prioritization

5.3.1.1 Strike targets are prioritized based on a weighted decision function. The example formula shows the prioritization number to be a linear combination of perceived probabilities times the weight. Can other types of prioritization algorithms be used? Say maybe two brigades located at a node is worth 3 times what one at a node is rather then just 2 times as in the example. Can the analyst incorporate such changes at the beginning of the game and/or during game play? Kruse

5.3.1.2 The same comment basically holds for route assignment and other such processes. In other words, the analyst has the ability to select between different attrition algorithms. Will such selections be available for other algorithms in the model?

Kruse

5.3.2 Strike mission allocation

5.3.2.1 Need a probability of success (or losses incurred) to balance value of attacking. If you are shooting artillery at a target, it might be sufficient to look for biggest concentration of value; however, if you are sending manned aircraft or air mobile troops at target, you might want to look for big enough to be worthwhile but small enough to win. Hartley

\subsection{Logistics Attrition} some sometimes. Similar losses can be applied to the supplies (both air transported and ground transported).

Hartley

5.4.0.2 The only comment I have is that accounting for the interdiction of our own supplies is critical. The interdiction of our supplies should be viewed as something the opponent will focus on as a critical failure point. I don't have a problem with the "backward-accounting" approach mentioned, so long as it is integrated into the expected COAs of the opponent.

Martellaro 
6. MNS ITEMS

6.0.1 The following things are unknowns (to me):

Time required for a study (both setup and execution).

Current set of J-8 tools.

Components or elements of a study scenario.

Resources, methods, and tools used to setup and run a scenario.

Skills and capabilities of the end-users.

Implementation of the corrections to the identified deficiencies.

Computing resources identified in the J-8 Analytical Suite Project Management

Plan (PMP).

Thomas

6.1 Short Time to Set Up, Run and Analyze many and different friendly and enemy COAs, operational concepts, threat employment scenarios, and force mixes

6.1.1 ambitious project. Specifically: Rapidly set up and vary concepts and scenarios...

Packard

6.1.2 How much time? A better understanding, via example, of the resources required to setup and run a job would be nice.

Thomas

GOAL IS RUN TIME OF ABOUT 30 MINUTES. THIS MEANS THAT THE REPLICATIONS FOR ONE EXCURSION CAN BE RUN OVER NIGHT (USING A MULTIPROCESSOR WITH ONE REP PER PROCESSOR).

6.1.3 How many is many different possible friendly and enemy courses of action within a study scenario? How different is different?

Thomas

6.1.4 If one goal is to reduce the turn around time for analysis, there should be a comparison of the volume of input (and output) data, by category, of current models and FTLM. Hartley

6.1.5 The number of required stochastic runs is estimated to be small. That's a pretty bold statement to make prior to an analysis of the typical variances.Martellaro

6.2 Incorporate Uncertainty in data, scenarios (multiple regional contingencies), processes, and represent and measure variability of theater outcomes

6.2.1 So, is there any way to design parts of the model to be less sensitive to input, or are they just going to handle it my making the whole model itself a sensitivity analysis tool.

Kruse

THREE KINDS OF INPUT VARIABLES: EXPERIMENTAL VARIABLES, EXPERIMENTAL VARIABLES/UNKNOWN FACTORS, AND REAL WORLD VARIABILITY. EXPERIMENTAL VARIABLES CATEGORY CONTAINS THOSE GIVEN IN THE PROBLEM STATEMENT OR DERIVED FROM THE PROBLEM STATEMENT. THE QUESTION IS TO DETERMINE WHAT DIFFERENCE THEIR VARIATION MAKES. THE EXPERIMENTAL VARIABLES/UNKNOWN FACTORS CATEGORY CONTAINS VARIABLES THAT NEED TO BE VARIED BECAUSE THEY CANNOT ALL BE CONTROLLED. EXAMPLES ARE ACTUAL ARRIVAL TIMES (VS PLANNED ARRIVAL TIMES) OF FORCES IN THE FIRST PART OF THE CATEGORY AND FIGHTING EFFECTIVENESS OF FORCES IN THE SECOND PART OF THE CATEGORY. REAL WORLD VARIABILITY VARIABLES INCLUDE WEATHER, STOCHASTIC ATTRITION, AND PERCEPTIONS OF REALITY. 
6.3 Joint and Combined Theater of Operations with Relatively Smaller (compared to European scenarios of 70's and 80's), and Highly Mobile Forces

6.3.1 Clarify "large-scale and complexity" with respect to force sizes, structures, and mixes. Clarify "small highly mobile forces."

Thomas

6.4 Air and Ground Combat in Joint Theater with Naval Impact on Ground, Littoral and Air Combat

6.4.1 How will naval impacts be implemented? Will ships be nodes in the sea? Will they move?

Hartley

6.4.2 There is no mention of a naval maneuver model (surface, sub-surface, amphibious, and air components). Will there be a requirement for one? I would expect the amphibious units (Marine Corps) would become ground maneuver elements when they landed. J-8/CAD has NAVMOD (at least they did when I ran it back in 1987). This model may have been incorporated into TACWAR by now.

Turley

6.4.3 Integrating the different philosophies and workings of the Air Force and Army is severely glossed over. Should a new metaphor for the operation of FTLM, in turn, drive the military thinking about cross-service cooperation? If not, then we'll end up letting current coordination methods remain out of synch with a model that cannot recognize those divisions.

Martellaro

6.5 Incorporate Operational $C^{3}$ I Explicitly, Showing Effects on Outcomes

6.5.1 Ambitious project. Specifically: Effects of $C^{3} I \quad$ Packard CURRENT FORCE STRUCTURE QUESTIONS INVOLVE SUBSTTTUTING INFORMATION TECHNOLOGIES FOR FORCE STRUCTURE SO MUST BE ABLE TO PORTRAY COST OF POOR INFORMATION. THERE WILL BE A GREATER VARIATION OF SCENARIOS. AND NEED DISTRIBUTIONS OF OUTPUT VARIABLES. DRIVER IS $C^{3}$ I: MEASURE THE CONTRIBUTION OF $C^{3}$ I SYSTEMS BY ONE SIDE OR BOTH AND EFFECT OF LOSSES TO THESE SYSTEMS; SHOW THE ROBUSTNESS OF A FORCE STRUCTURE TO DECISION MAKING, OPERATIONAL MANEUVER, AND OPERATIONAL INTELLIGENCE; SHOW THE VARIABILITY INHERENT IN THE OUTCOME WHEN DIFFERENT OPERATIONAL CONCEPTS AND PERCEPTIONS ARE REPRESENTED; MAY SUPPORT BROAD MEASURES OF FORCE-LEVEL EFFECTIVENESS OF $C^{3}$ I CAPABILITIES. WILL NOT HAVE RESOLUTION TO ADDRESS MOST WEAPON SYSTEM ISSUES, E.G., M1A1 VS M1A2; HOWEVER, MAY ADDRESS NEW CAPABILITY SYSTEMS, E.G., LONG RANGE ABILITY OF MLRS VS NO MLRS.

6.6 Easily Display and Model Maneuver-Based Warfare

6.6.1 Ambitious project. Specifically: combined with 12.6 ground, air, \& naval, displaying entities which function at radically different physical speeds and with radically different effects per warrior can be difficult... just to decide what scale best applies.

Packard HEART OF QUESTION IS MRCS. E.G., CONSIDER IMPACT OF 2 MRCS IN TERMS OF LIFT AVAILABILITY. 50-70 PHYSICAL GROUND NODES PER THEATER.

6.6.2 Clarify the requirements for "easy" (to whom), "rapid" (how fast), and "representation" (what's best).

Thomas 
6.7 Deployment and Sustainment Effects

6.7.1 How will variable introductions of forces and materiel be computed and handled?

Hartley

6.8 Effects of Chemical and Nuclear Weapons

6.8.1 How will chemical and nuclear weapons be modeled?

Hartley

6.9 Effects of Qualitative Factors, such as Leadership, Training and Morale 6.9.1 How are these factors to be implemented?

Hartley

6.10 No Extensive Personnel Requirements (J-8 can set up, run and analyze the model themselves)

6.10.1 References to end-users are inconsistent (is this intentional or incidental). Often referred to as "analyst", "people", and "Joint Staff personnel who must enter data and validate results without support". What might the "without support" mean?

Thomas

6.11 Use J-8 Standard Hardware, Software and Operating System Set, But also Portable to Other Hardware and Operating Systems

6.11.1 ".. supportable using hardware, software, and operating systems identified in J-8 Analytical Suite PMP ..." Can we get a description of that hardware, software, and operating systems environment?

Packard

6.11.2 Does this mean no proprietary systems? Does this mean "only commercial off the shelf" products? Does this mean only the hardware defined in the PMP?

MACHINE RESTRICTION IS POSIX AND X-WINDOWS.

Thomas

6.11.3 All the output calculations must be output to the user in a very special way. There should be excessive and healthy discussion about how to best display this information. Numbers in nine point type on a $40 \mathrm{~cm}$ monitor will not cut it with Generals.

Martellaro

6.11.4 I Urgently and Strongly suggest that FTLM get away from small monitors and mice. I think the project needs to think about other display and input technologies FOR THE END USER. It's OK to do the programming with CRTs and mice. It's not OK to force that technology onto Generals and Colonels. Otherwise, they'll just finance a new system. As I understand it, instead of techies spending months setting up scenarios, this tool is to be used by high-level leadership in an interactive and stochastic mode. They'll need a different kind of system. I recommend something like large horizontal LCD maps with "touch and drag" manipulation.

Martellaro

6.12 Must Be Written in Ada - Unless Waiver Is Asked for and Given

6.12.1 Does Ada operate in that environment?

Packard

6.12.2 Ada does not support Object Oriented Programming fully. What impact will this have? DMSO IS HINTING THAT ADA REQUIREMENT WILL GO AWAY.

6.12.3 I strongly recommend $C^{++}$.

Martellaro 
6.13 Must Have Complete Mathematical Description and Tutorial for Analysts in How To Convert the Analyst's War to the Model

6.13.1 This is very important.

Hartley

6.14 Must Incorporate IV\&V Concurrent with Design and Test

6.14.1 This is also very important.

Hartley

\section{MAJOR ISSUES}

7.1 Input Tools

7.1.1 The MNS goal of rapid turnaround generates a requirement of either an impractically small input data stream or a sophisticated set of user tools for creating, modifying and validating the FTLM input. This facility should be planned now in the same way the model is planned.

Hartley

7.1.2 Determine causes for long setup times (e.g., technology, personnel, data collection, or other). Consider some means to duplicate or replicate scenarios to help reduce or minimize the setup time. Consider use of parallel or distributed processing for timeliness. Develop some means to decompose the model to help minimize the complexity and to support parallel and/or distributed processing. Seems that an application-oriented GUI would be nice. Computer-aided training module that incorporates the use of optical disk technologies to support training and on-line help. NOTE: The computing requirements defined in the $M N S$, and in the PMP, may prohibit use of some of the above computing technologies.

Thomas

7.1.3 In addition to describing the model workings, an equal if not greater amount of effort should be spent describing how the user interface will allow the J-8 members to meaningfully run the model themselves - without a supporting cast of thousands. That will require new levels of sophistication in the man-machine interface.

Martellaro

7.1.4 When considering a stochastic model and variable outputs, the difficulties of variable inputs are sometimes overlooked. While the output result can be a simple number (for example, $70 \%$ chance of success), the user interface required to propagate alternative inputs into the code is ignored - and that's why previous models take so long to set up.

Martellaro

7.1.5 Need a design for the user interface. It needs to be done RIGHT AWAY. A lot of the programming will be dictated by how the user is going to interact with the system, and trying to add that later will be a fatal mistake. This is the most important thing I can say and the most likely cause for failure of the project later.

Martellaro

7.1.6 Lots of comments about user interface, input to make easy and easy to validate and output to make analysis easy, consistent, complete, etc., especially considering comparison of variations. Hartley

7.1.7 Set up forces - this really requires a GUI and extensive source data. The GUI would lead the analyst rapidly through the set up steps, offering menus and radio buttons to select from predictable options and collecting non-standard elements to offer during future excursions. A common US DOD and or Jane's Library data base should be the root source with tailored and tailorable additions. $A$ 
candidate source is the combination of Conventional Force Data Base (CFDB) and Master Simulation Data System (MSDS). Once generic units are available, placing them is a relatively easy activity when supported by $a$ map-based GUI. Determining and entering the unit orientation (direction of majority of combat effectiveness) and support relationship is more difficult.

Particularly in a joint or combined scenario, the following type of questions are hard to answer, but terribly important: Which support elements are responsible for which combat elements? Which are interchangeable? Which can support multiple combat units? For how long? This type of detail is often required and available only from the parent command of the units involved. A relational and/or object-oriented data base is recommended. Units of a given type should have given characteristics and performance, but unique units should be "creatable" by inheriting the generic characteristics and adding special elements and functions.

Packard

7.1.8 One of the major things to be learned from CASTFOREM is the need for designing a good user interface at the front end. This greatly reduces the total system cost, increases the flexibility of the model, vastly decreases the turn around time for a study, permits more and better post run analyses, and ensures better quality by reducing errors in the study.

Hartley

7.2 Data Storage

7.2.1 How may people and months of preparation do they expect FTLM to require to run. I see no discussions on the possibility of using a database for the parameters and probabilities. And what consideration have they given to an input and editing tools for scenarios and such.

Kruse

7.2.2 FTLM will need output support system to capture output data and support rapid, reliable and meaningful analysis of the complex output. Hartley

7.3 Analytic Tools

7.3.1 Similarly, the output analysis needs to be planned now. Hartley

7.3.2 Page 7: FTLM output should be designed with statistical software interoperability in mind, be it SAS or another. Packard

7.3.3 Territorial ownership as an MOE could be calculated using a concept of cellular automata: neighbors. That is, node and link ownership depends on proximity and/or time since last occupancy by a combatant.

Hartley

7.3.4 Must think a lot about sensitivity analyses. What model interactions drive the variability? There should be a sub-process built into the model which can estimate the influence of any variable. Then it can be turned off and the model will run faster with no decrease in fidelity.

Martellaro

7.3.5 He gets it exactly right: "How sensitive are my conclusions to the values I selected."

Martellaro

7.4 Environment Definition

7.4.1 Needs content.

Hartley 
7.5 Decision Logic

7.5.1 There is not enough discussion about the rule sets and how they are to be implemented. How are the rule sets specified. Are they specified as in expert system rule base type rules such as "if this happens then do that" or are any of the rules based in a more mathematical type algorithm (example, like in Glenn Allgood's work)?

Kruse

7.5.2 Constructing the rule sets for FTLM will be a huge undertaking. How will the rule sets be validated (and by whom), especially for completeness? How will these rule sets be constructed? Will an expert system or neural net approach be used? Since there will be so many rules to process, perhaps a pruning methodology should be used to eliminate testing all the rules. Only rules pertaining to a certain situation (a grouping) would be tested: a branch of the decision tree would be traversed.

Turley

7.5.3 Have to watch for "grandfathered" rule sets becoming used without understanding vs. the problem of users not wanting to use the model because it would be "too hard" to come up with rules.

Hartley

7.5.4 I worry about the advisability of not accepting feedback from the field in a high level COA device. The tendency is to want to model processes that represent large-scale actions in order to force stochasticism. For a more detailed modeh, I can do that. I can model a tank main gun and estimate, based on weapons data, what the probability is that a round will strike an enemy tank in the turret, turret ring or the tracks. I do that because I can't ask the round where it's going to hit. (No humor intended.) But I *an* pick up the phone and ask a Battalion Commander what he intends to do. He says, "if it rains before sunset, I advance. If not, I wait until dark. And I'm doing that because....) You have to take things like that into consideration when generating stochastic runs on a Theater level model. Otherwise, the model becomes hopelessly disconnected from reality.

Martellaro

7.5.5 Document says "Constraints representing part of the air campaign plan (COA) may be established by the user to restrict the valid path set." Are these constraints given in the form of a generalized rule set that the user adds to the model rule set, or are they part of a particular mission plan?

Kruse

7.6 Data Availability

7.6.1 Will the data needed for FTLM be obtainable? Have the data been identified (in any way)?

Hartley

7.6.2 Pages 2-3 address US forces. The database needs to be developed with a new world order / combined force mentality. The Republic of Korea has 55 divisions as compared with one US division. Allied may have old soviet weapons and training and / or old US weapons. Opposing forces may have US weapons and training. Neutrals could have anything. Terrorists and less sophisticated combatants may used mixtures of weapons, doctrine, and organization previously not encountered.

Packard

7.7 Documentation

7.7.1 Subsequent design documents should be more specific in distinguishing between general discussion and concepts which can be modeled. To identify weaknesses of older models and combine that with "here's what we should do" arguments 
is not equal to defining a methodology or basis for quantitative modeling.

Martellaro

7.7.2 The analyst's guide for the FTLM will need to include guides for modeling the scenario through choice of the nodellink architecture. Terrain with clearly defined avenues of approach and objectives are relatively easy to model. There are some potential areas of difficulty. For instance high points may be good defensive positions. In some situations these will be objectives; however, they may not be actually nodes on the travel paths. It may be good practice to allow bypassing some objectives with a node before and after that node and a link around it. Alternatively, a city may be a realistic node that may need to be taken or bypassed.

A situation that is difficult to model is open territory. Some nodes are obvious, such as cities, fortifications, etc. However, the paths that may be taken are infinite. One modeling approach is to generate many alternate links between nodes. This has the problem of opposing forces on parallel paths always being unable to attack each other. Another approach is to generate one link with great width and an associated probability of not seeing another force on the link. Thus opposing forces might see each other or might miss each other. This has the problem of no permitting changes in destination in mid trip (over perhaps long distances), which would actually be possible. A solution could be to generate notional (not attached to any real terrain feature) fixed nodes in the middle of such links, connected to other mid-link nodes. Hartley

7.7.3 The analysis of the COAs in Schmidt's thesis says that COA \#3 was perceived as the one being pursued even when $C O A \# 1$ and when $C O A \# 2$ were the actual COAs being pursued. An examination of the scenario shows that at the first part of the action, Avenues of Approach \#1 and \#2 were confounded and at the end $A A$ \#2 and \#3 were confounded. Further, the COA definitions made distinguishing very difficult because the differences lay largely in the actions of the infantry brigades and the mechanized brigades, which are more difficult to detect and distinguish. This might be a true representation of reality, not a flaw in the model! The FTLM analyst documentation must make it clear how important it is for the analyst to make sure he or she understands the native distinguishability of the COAs. Further, less distinctive COAs might require less subtlety in possible deception plans, otherwise the enemy might acquire the deception, believe it, yet still act in what ends up being the proper fashion for the enemy.

Hartley

7.8 Management

7.8.1 Need a concept for the development system. POSIX and $X$ are fine. There should be a survey of CASE tools and exploration done on how the software project and code will be managed. The last thing that should be done, on a model of this importance, is to just sit down and start writing (undisciplined) code in "vi" and starting to compile. There needs to be a Source Code Control System agreed on. A system needs to be developed for the cooperation but non-interference of multiple authors. For example, it is critical that each programmer be able to exercise and test his/her own changes, but it must be done in a common system in which the baseline and core code can be 
standardized and controlled. A graphical CASE tool which can show the relationships of the modules \& objects should be explored.

Martellaro 


\section{DISTRIBUTION}
1. C. D. Doty
2. D. M. Hetrick
3. R. B. Honea
4. H. L. Hwang
5. B. L. Kirk
6. K. L. Kruse
7. A. S. Loebl
8. J. R. Merriman
9. A. J. Martellaro
10. H. C. Martellaro
11. S. L. Packard
12. V. Protopopescu
13. A. H. Rice
14. R. T. Santoro
15. J. D. Shelton
16. K. W. Sommerfeld

\author{
17. M. S. Smith \\ 18. P. M. Tarrant \\ 19. R. W. Taylor \\ 20. B. E. Tonn \\ 21. B. Thomas, Jr. \\ 22. J. P. Trien \\ 23. V. K. Turley \\ 24. D. P. Vogt \\ 25. R. C. Ward \\ 26. G. W. Westley \\ 27. J. W. Wooten \\ 28. DSRD Resource Center \\ 29. Applied Technology Library \\ 30. K-25 Site Records \\ 31. A. S. Quist \\ 32. A. S. Quist (OSTI \#1) \\ 33. A. S. Quist (OSTI \#2)
}

34. Office of Assistant Manager for Defense Programs, DOE, Oak Ridge Field Office, Oak Ridge, TN 37831.

35. Dept of Operations Research, Air Force Institute of Technology, Code: ENS, Wright Pat AFB, OH 45433.

36. HQ US European Command, Code: ECJ5-E, APO New York, NY 09128-4209.

37. HQ US Forces Command, Code: FCJ5-PP, Fort McPherson, GA $30330-6000$.

38. HQ US Special Operations Command, Code: J-5Y, MacDill AFB, FL 33608-6001.

39. Naval War College, Sims Hall, War Gaming Dept, Newport, RI 02841-5010.

40. Commander, TRAC, ATTN: ATRAC-TD, Fort Leavenworth, KS 66027-5200.

41. HQ TRAC, RPD, ATTN: ATRC-RPP, Fort Monroe, VA 23651-5443.

42. Director, US Army Materiel Systems Analysis Activity, ATTN: AMXSY-LM, Aberdeen Proving Ground, MD 21005-5071.

43. Director, US Army Ballistic Research Laboratories, ATTN: SLCBR-D, Building 305, Aberdeen Proving Ground, MD 21005-5066.

44. Commander, US Army Training and Doctrine Command, ATTN: ATIM-OPM, Fort Monroe, VA 23651-5000.

45. Commandant, US Marine Corps, ATTN: HQSR-3, Washington, DC 20380.

46. JWC-OR, Joint Warfare Center, P.O. Box 1000, BLD 90005, Hurlburt Field, FL 32544.

47. JWC-TA, Joint Warfare Center, Hurlburt Field, FL 32544.

48. Dr. Paul J. Berenson, Scientific Advisor to the Commanding General, U.S. Army Training and Doctrine Command, Fort Monroe, VA 23651-5000.

49. James N. Bexfield, System Evaluation Division, Institute for Defense Analyses, $1801 \mathrm{~N}$. Beauregard St, Alexandria, VA $22311-1772$.

50. Lt. Col. Bolyard, HQ US Southern Command, Code: SCJ5TRA, APO Miami, FL 34003-0300.

51. Steve Bravy, BMDO/GSS, Room 1E149 Pentagon, Washington, DC 20301-7100.

52. Pete Byrne, The Joint Staff/J-8, Rm 1D929, The Pentagon, Washington, DC 20318-8000.

53. L. Cantwell, Director TRAC-FLVN, Fort Leavenworth, KS 66027-5200.

54. Col Cary, Center for Strategic Wargaming, U.S. Army War College, Carlisle Barracks, PA 17013-5050.

55. Chief, Exercise Division, FKJ3-ED, ATTN: Col. Gary A. Chilcott, PSC 303, Box 27, APO AP 96204-0027.

56. Julie C. Chu, USARDEC, ATTN: SMCAR-ASH, Bldg 1, Picatenny Arsenal, NJ 07806-5000.

57. Lloyd Clark, AFSAASAM, 1570 Air Force Pentagon, Washington, DC 20330-1570.

58. Douglas E. Cook, Operations Analysis, DCS, Operations, Department of the Air Force, Headquarters Pacific Air Forces, Hickam Air Force Base, Hawaii 96853-5001.

59. Col Fred D. Cooper, Department of the Army, Deputy Chief of Staff for Intelligence (DAMI-AM), The Pentagon, 2E479, Washington, DC 20310-1001. 
60. LTC Ross E. Dickinson, Joint Wartighting Center, 246 Harston St, Hurlburt Field, FL 32544.

61. Louis D. Duncan, Firepower Branch, USALABCOM, US Army Atmospheric Sciences Laboratory, WSMR, NM 88002-5501.

62. S. Frank, JDSSC/C315, Rm ME651, The Pentagon, Washington, DC 20301-7010.

63. Bruce W. Fowler, USAMICOM, ATTN; AUSMI-RD-AC, Redstone Arsenal, AL 35898-5242.

64. John L. Freeman, DMSO, 1901 N. Beauregard, Suite \#504, Alexandria, VA 22311.

65. LTC Gene Glasser, The Army Reuse Center, U.S. Army Information Systems Software Development Center Washington, ATTN: ASQB-IWE-R, Stop H-4, Fort Belvoir, VA 22060-5456.

66. Dave Gledhill, Illgen Simulation Technologies, Inc., 250 Storke Road, Ste \#10, Goleta, CA 93117.

67. SHAPE Technical Centre (STC), ATTN: Mr. Rex Goad, Acting Chief, Operations Research Division, The Hague, Netherlands, APO New York 09159.

68. Commander, I Corps and Fort Lewis, ATTN: AFZH-GTS (Mr. Keith Grant), Fort Lewis, WA 98433.

69. Stan Gray, TRADOC Analysis Command, ATRC-WAB, WSMR, NM 88002.

70. Ms. Carolyn Guy, J-8, Room 1D-940, The Pentagon, Washington, DC 20318-8000.

71. R. Hadala, USAEWES, P.O.Box 631, Vicksburg, MS 39180.

72. Dave Hall, Naval Air Warfare Center, Weapons Division, C21806, China Lake, CA 93555-6001.

73. Kent Haspert, IDA, 1801 N. Beauregard St., Alexandria, VA 22311.

74. Dr. Henningsen, OSD-PA\&E, Room 2B-256, The Pentagon, Washington, DC 20301.

75. Col John J. Hickey, Jr., Box 481, USAWC, Carlisle, PA 17013.

76. Col. Hogan, National Defense University, Ft MCNair, Washington, DC 20319.

77. Gerard Hufstetler, Aviation Applied Technology Directorate, Aviation and Troop Command, AMSAT-R-TDRP (ATTN: G. Hufstetler), Fort Eustis, VA 23604-5577.

78. Ms. Glenna Hughes, OSD-Net Assessment, Room 3A-930, The Pentagon, Washington, DC 20301.

79. US Naval Postgraduate School (NPGS), Code 55HL, ATTN: Prof CAPT Wayne P. Hughes, Jr., Monterey, CA 93943.

80. R. Humphrey, 1055 Ritner Highway, Shippenburg, PA 17257.

81. Institute for Defense Analyses (IDA), 1801 North Beauregard St, ATTN: Edward Kerlin, Alexandria, VA 22311.

82. Mr. Dennis Konkel, Center for Strategic Wargaming, U.S. Army War College, Carlisle Barracks, PA 170135050.

83. Ken Konwin, AFSAA/SAZ, 1570 Air Force Pentagon, Washington, DC 20330-1570.

84. Col Krieger, The Joint Staff/J-5, Room 2E-949, The Pentagon, Washington, DC 20301.

85. Mr. Lavoie, AUCADRE, Bldg 1406, Maxwell AFB, AL 36112-5532.

86. Dr. Lese, OSD-PA\&E, Room 2B-256, The Pentagon, Washington, DC 20301.

87. William G. Lesso, Department of the Air Force, The Department of Economics and Geography, United States Air Force Academy, Colorado 80840-5701.

88. Robert O. Lewis, General Research Corp, 635 Discovery Drive, Huntsville, AL 35806.

89. R. W. Meier, CEWES-GM-L, USAE-WES, 3909 Halls Ferry Road, Vicksburg, MS 39180.

90. LTC Meiers, HQ US Space Command, Code: AN, Peterson AFB, CO 80914-5000.

91. Lt Col Michael L. Metz, OSD-Net Assessment, Room 3A-930, The Pentagon, Washington, DC 20301.

92. Department of the Army, Office of the Deputy Chief of Staff for Operations and Plans, ATTN: DAMO-ZDS (Mr. Jim Metzger), Chief, Studies and Analysis Division, Washington, DC 20310-0400.

93. Major Ray Miller, HQ USAF/XOMT, 1480 Air Force Pentagon, Washington, DC 20330-1480.

94. Roshelle B. Orgusaar, 46TW/TSWW, 401 W. Choctawhatchee Ave, Ste \#265, Eglin AFB, FL 32542.

95. Capt Pacek, The Joint Staff/J-7, Room 2B-865, The Pentagon, Washington, DC 20301.

96. Director, US Army TRADOC Analysis Command, ATTN: ATRC-WE (Dr. Randall M. Parish), White Sands Missile Range, NM 88002-5502.

97. Steve G. Payne, DIA/MSIC, MSC-6B, Bldg. 4505, Redstone Arsenal, AL 35898-5500.

98. Paul Reeves, NCCOSC RDTE Division (78), 49590 Lassing Rd, San Diego, CA 92152-6145.

99. Mr. John Roley, Director: Center for Strategic Wargaming, U.S. Army War College, Carlisle Barracks, PA 17013-5050.

100. Dr. Patricia Sanders, ODPA-E, Pentagon, Rm 2B256, Washington, DC 20301-1800.

101. Dennis Shea, Center for Naval Analysis, 4401 Ford Ave, Alexandria, VA 22302.

102. LTC Jude Shea, Director, Battle Simulation Center, FKJ3-ED-BSC, PSC 303, Box 27, APO AP 96204-0027.

103. George F. Stone III, Wargaming Lab, Operations Research Center, Mahan Hall, United States Military Academy, West Point, NY 10996.

104. Chief, Exercise Division, FKJ3-ED, ATTN: Mr. Lyle Suprise, PSC 303, Box 27, APO AP 96204-0027.

105. Headquarters, US Air Force, Assistant Chief of Staff for Studies and Analyses, ATTN: AS/SAS (Mr. Clayton Thomas), Room 1E386, The Pentagon, Washington, DC 20330-5420. 
106. LtCol Dave Thomen, Studies \& Analysis Division (C-452), 3093 Upshur Ave, MCCDC, Quantico, VA 221345130.

107. Dr. J. J. Tritten, Naval Postgraduate School, Monterey, CA 93943.

108. The Joint Staff/J-7, ATTN: Col David L. Vesely, Rm 2B877, The Pentagon, Washington, DC 20318-7000.

109. Director, US Army Study Program Management Agency (SPMA), ATTN: SFUS-SPM (Mr. Visco), The Pentagon, Room 3C559, Washington, DC 20310-0102.

110. TRAC-OAC, ATTN: ATRC-FZ, Ft. Leavenworth, KS 66027.

111. Pat Wheeler, AFSAASAM, 1570 Air Force Pentagon, Washington, DC 20330-1570.

112. Howard G. Whitley III, US Army Concepts Analysis Agency, 8120 Woodmont Ave, Bethesda, MD 208142797.

113. Dr. Daniel Willard, Department of the Army, SAUS-OR, The Pentagon, Washington, DC 20310-0102.

114. LTC (P) S. Doug Williams, Center for Strategic Wargaming, U.S. Army War College, Carlisle Barracks, PA 17013-5050.

115. LtCol Mark Youngren, J-8/CFAD, Room 1D-940, The Pentagon, Washington, DC 20318-8000.

116. J. Bracken, PO Box 151048, Chevy Chase, MD 20815.

117. L. G. Callahan, Jr., Georgia Institute of Technology, School of Industrial Systems Engineering, Atlanta, GA 30322.

118. Y. Chan, Air Force Institute of Technology, Wright Patterson AFB, OH 45433.

119. W. P. Cherry, Vector Research, Inc., P.O. Box 1506, Ann Arbor, MI 48106.

120. Col T. Dupuy, 1324 Kurtz Road, McLean, VA 22101.

121. Stephen T. Dziuban, Logicon RDA, 105 E. Vermijo Ave, Ste \#450, Colorado Springs, CO 80903.

122. S. A. Erickson, Jr., Lawrence Livermore National Laboratory, MS L83, UC Box 808, Livermore, CA 94550.

123. A. Gafarian, University of Southern California, Industrial and System Engineering, Los Angeles, CA 900890193.

124. R. Helmbold, U.S. Army Concepts Analysis Agency, 8120 Woodmont Avenue, Bethesda, MD 20814-2797.

125. E. Kelleher, Rolands and Associates, 500 Sloat Ave, Monterey, CA 93940.

126. Peter L. Knepell, Logicon RDA, 105 E. Vermijo Ave, Ste \#450, Colorado Springs, Co 80903.

127. K. Ng, Operational Research \& Analysis Branch, Department of National Defence, 101 Colonel By Drive, Ottawa, Ontario, Canada K1A OK2.

128. S. H. Parry, Naval Postgraduate School, Monterey, CA 93943-5000.

129. P. Purdue, Naval Postgraduate School, Monterey, CA 93943-5000.

130. V. Roske, The Joint Staff/J-8, Rm 1D929, The Pentagon, Washington, DC 20318-8000.

131. R. I. Wiles, Military Operations Research Society, Landmark Towers, Suite 202, 101 S. Whiting St., Alexandria, VA 22304.

132. N. K. Womer, The University of Mississippi, Department of Economics and Finance, University, MS 38677 .

133. Dr. Clinton J. Ancker, Department of Industrial \& Systems Engineering, University of Southern California, University Park, Los Angeles, CA 90089-0193.

134. Robert Anderson, RAND, PO Box 2138, Santa Monica, CA 90407-2138.

135. S. Bailey, RAND Corporation, P.O. Box 2138, Santa Monica, CA 90406-2138.

136. Steve Bankes, RAND, PO Box 2138, Santa Monica, CA 90407-2138.

137. Bary Belian, Textron Defense Systems, 1915 Aerotech Dr, Suite 114, Colorado Springs, Co 80916.

138. Bart Bennett, RAND, PO Box 2138, Santa Monica, CA 90407-2138.

139. Vernon M. Bettencourt, Jr., MITRE, Washington C3I Division, 7525 Colshire Dr., McLean, VA 22102-3481.

140. Joe Bolmarcich, QUANTICS Inc., 5 Country View Road, Malvern, PA 19355.

141. Gregory Born, RAND, PO Box 2138, Santa Monica, CA 90407-2138.

142. G. H. Burgin, Titan Systems, Inc., 5910 Pacific Center Blvd, San Diego, CA 92121.

143. Monti Callero, RAND, PO Box 2138, Santa Monica, CA 90407-2138.

144. Joseph J. Cynamon, MITRE - ESC/MASC, 202 Burlington Rd, Bedford MA 01730.

145. Paul K. Davis, RAND, 1700 Main St, PO Box 2138, Santa Monica, CA 90407-2138.

146. Jim Dewar, RAND, PO Box 2138, Santa Monica, CA 90407-2138.

147. Dr. Stephen G. Downes-Martin, PO Box 151, Westminster, MA 01473.

148. James F. Dunnigan, 328 W. 19th Street, New York, NY 10011.

149. Brookings Institution, 1775 Massachusetts Avenue, NW, ATTN: Dr. Joshua Epstein, 797-6040, Washington, DC 20036.

150. Vector Research, Inc., ATTN: Mr. Robert Farrell, PO Box 1506, Ann Arbor, MI 48106.

151. Bill Flanigan, DISA/Center for Standards, 11440 isaac Newton Square, Suite 210, Code TBCF, Reston, VA 22090-5006.

152. D. P. Gaver, Naval Postgraduate School, Monterey, CA 93943-5000.

153. Richard A. Greene, RAND, 1700 Main St, PO Box 2138, Santa Monica, CA 90407-2138. 
154. L. Grike, MITRE Corporation, 7525 Colshire Dr., MCLean, VA 22101.

155. T. R. Gulledge, Dept. of Decision Sciences, George Mason University, 4400 University Drive, Fairfax, VA 22030.

156. C. F. Hawkins, Data Memory Systems, Inc., 10392 Democracy Lane, Fairfax, VA 22030.

157. Anthony Hearn, RAND, PO Box 2138, Santa Monica, CA 90407-2138.

158. Timothy J. Horrigan, Horrigan Analytics, $1460 \mathrm{~N}$. Sandburg Terrace, Suite 1001, Chicago, IL 60610.

159. P. A. Jacobs, Naval Postgraduate School, Monterey, CA 93943-5000.

160. Dr. Charles W. Johnson, Director, Center for the Study of War and Society, 220 Hoskins Library, The University of Tennessee, Knoxville, TN 37996-0411.

161. J. Kahan, Dynamics Research Corporation, 60 Frontage Road, Andover, MA 01810.

162. Iris Kameny, RAND, PO Box 2138, Santa Monica, CA 90407-2138.

163. Dr. Chris Landauer, The Aerospace Corporation, 13873 Prk Center Road, STe \#187, Herndon, VA 22071.

164. Maj. A. G. Loerch, 214 Brooktondale Road, Brooktondale, NY 14817.

165. Tom Lucas, RAND, PO Box 2138, Santa Monica, CA 90407-2138.

166. James H. M. Malley, 4920 Calle de Tierra N.E., Albuquerque, NM 87111.

167. Maynard Marquis, United Technologies Sikorsky, Advanced Design and Business Development, North Main St, Stratford, CT 06601.

168. Duncan C. Miller, MIT Lincoln Laboratory, 244 Wood St, Lexington, MA 02173-9108.

169. Peter C. Oleson, PO Box 132, Clifton, VA 22024.

170. Dr. Dale K. Pace, Johns Hopkins University/APL, Naval Warfare Analysis Dept, 1100 Johns Hopkins Rd, Laurel, MD 20723-6099.

171. Dr. Julian I. Palmore, Mathematics Department, University of Illinois at Urbana-Champaign, 377 Altgeld Hall, 1409 West Green St, Urbana, IL 61801.

172. A. Quattromani, SYSCON Corp., 2828 Penn. Ave NW, Washington, DC 20007.

173. R. J. Roland, Rolands and Associates, 500 Sloat Ave., Monterey, CA 93940.

174. Jeff Rothenberg, RAND, PO Box 2138, Santa Monica, CA 90407-2138.

175. Joseph M. Saur, PRC Inc., 468 Viking Dr, Virginia Beach, VA 23452.

176. Norman Shapiro, RAND, PO Box 2138, Santa Monica, CA 90407-2138.

177. James J. Sikora, BDM International, MS Y-10, 1801 Randolph Road, SE, Albuquerque, NM 87106.

178. Joseph A. Sladewski, ATCCS SE\&l, 788 Shrewsbury Ave, Tinton Falls, NJ 07725.

179. R. M. Toms, LLNL, Conflict Simulation Laboratory, U.C. Box 808, Livermore, CA 94550.

180. Clairice Veit, RAND, PO BOX 2138, Santa Monica, CA 90407-2138.

181. Pat Vye, TRADOC Research Associate, RAND, PO Box 2138, Santa Monica, CA 90407-2138.

182. Warren Walker, RAND, PO Box 2138, Santa Monica, CA 90407-2138.

183. The RAND Corporation, 1700 Main St, PO Box 2138, ATTN: System Science Department (Mr. Milton Weiner), Santa Monica, CA 90406-2138.

184. Dr. Marion L. Williams, HQ AFOTEC/CN, 8500 Gibson Blvd SE, Kintland AFB, NM 87117-5558.

185. Ben P. Wise, McDonnell Douglas Research Laboratories, Dept 225 Bldg 105, Mail Code 1065165, PO Box 516, Saint Louis, MO 63166-0516.

186. J. Ralph Wood, 1727 Redgate Farms Ct., Rockville, MD 20850.

187. Simone Youngblood, Johns Hopkins University/APL, Naval Warfare Analysis Dept, 1100 Johns Hopkins Rd, Laurel, MD 20723-6099.

188. BG Avraham Ayalon, $3 \mathrm{Ha}$ Ogen Street, Kfar Saba, Israel.

189. Amnon Gonen, TIL, Defence Systems, 7 Harugly Malkhut St., Tel-Aviv 69714, Israel.

190. Universitaet der Bundeswehr Muenchen, Fakultaet fur Informatik, Institut fur Angewandte Systemforschung und Operations Research, ATTN: Professor Dr.-Ing. Reiner K. Huber, Werner-Heisenberg-Weg 39, D-8014, Neubiberg, FRG.

191. Defence Operational Analysis Establishment (DOAE), Broadoaks, Parvis Road, ATTN: Field Studies Division (Mr. David Rowland), West Byfleet, Surrey, KT14 6LY, UK.

192. Centre for Operational Research and Defence Analysis (CORDA), ATTN: Professor Ronald W. Shephard, Associate Consultant, 22 Long Acre, London WC2E 9LY, UK.

193-225. D. S. Hartley III 